\title{
HAIORATORY DRECTIONS
}

\section{EOR

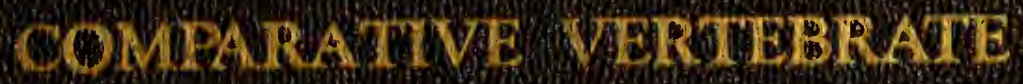 \\ ANAOTONY}

Gray

QL
812
G 82 


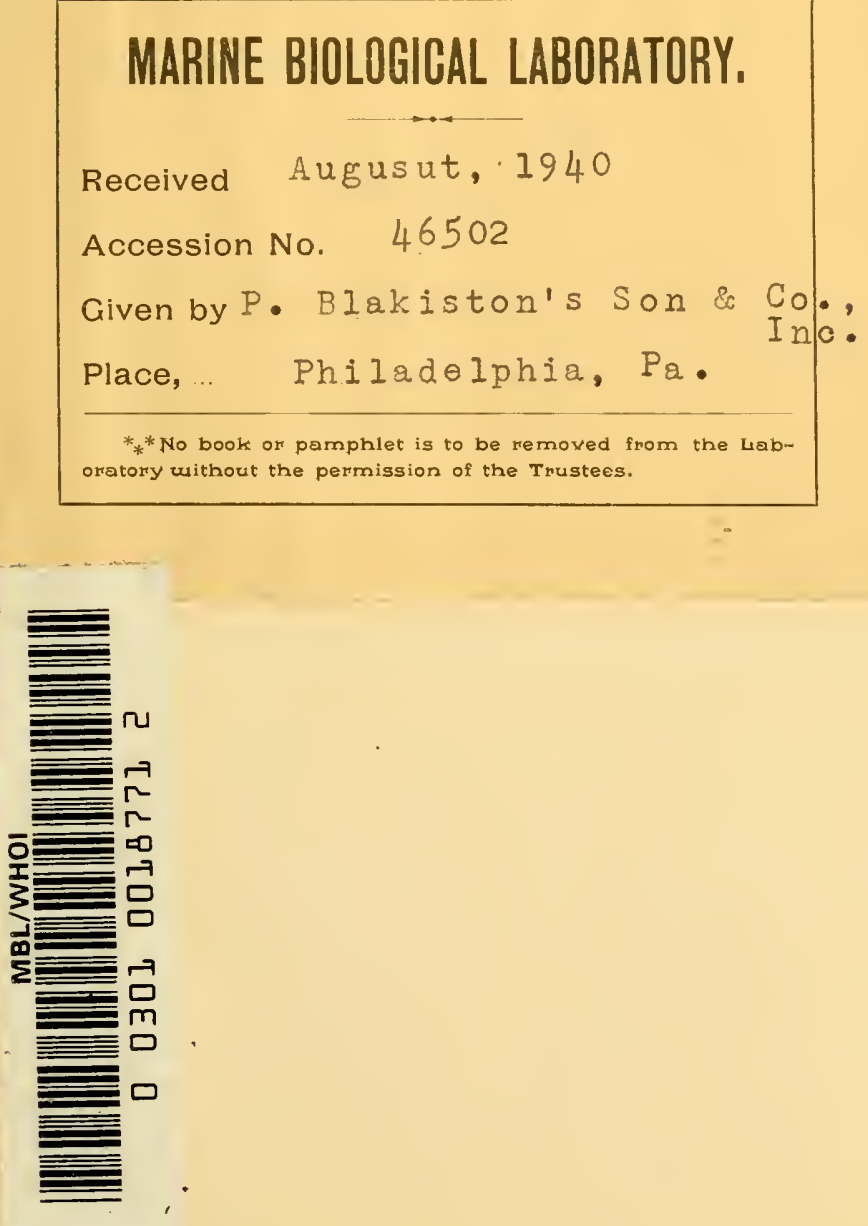
Laboratory Directions

for

COMPARATIVE VERTEBRATE

ANATOMY 



\title{
Laboratory Directions
}

\author{
for
}

\section{COMPARATIVE VERTEBRATE}

\section{ANATOMY}

\author{
By
}

\section{E. Gray, Ph.D.}

Associate Professor of Zoology,

Duke University

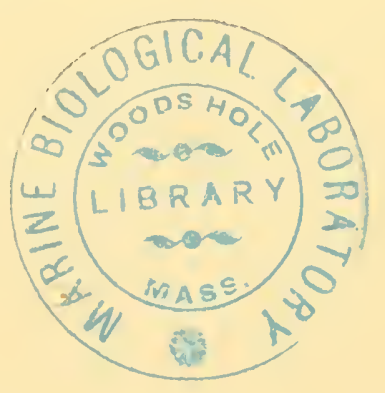

P. BLAKISTON'S SON \& CO., INC.

Philadelphia 
Copyright, 1938, by P. Blakiston's Son \& Co., Inc. 


\section{Preface}

This laboratory guide was designed for use in a one-semester course. It was written for the student-not the instructorand was planned to be used independently by the student with a minimum of aid from the instructor. The laboratory work is of course to be supplemented by readings, discussions, and lectures. Standard laboratory materials, shark, Necturus, and cat, are the principal animals used; and each organ system is treated in a comparative manner. Experience has taught that, although greater storage facilities are sometimes necessary, the comparative method of teaching vertebrate anatomy is superior to other methods. Specific mention of the drawings to be required of the student is purposely omitted; it seems better for each instructor to use his own judgment in this respect.

The author makes no claim to originality in writing this manual. As is the case with most laboratory guides ideas and information were derived from many sources. Special acknowledgment, however, should be made to Professor George Wagner of the University of Wisconsin, whose methods of presention have been followed to a considerable extent.

I. E. Gray.

Durham, N. C. 

VI. The Urogenital System . . . . . . . . 65

Shark. . . . . . . . . 65

Necturus . . . . . . . . . . . . . 67

Cat. . . . . . . . . . . 68

VII. The Nervous System. . . . . . . . . . . 7 I

Sense Organs. . . . . . . . . . . . . . $7 \mathbf{I}$

Ear. . . . . . . . . . . $7 \mathrm{I}$

Eye. . . . . . . . . . . . . . 72

Brain and Cranial Nerves . . . . . . . . . 74

Shark. . . . . . . . . . . 74

Cat. . . . . . . . . . . . . 77 


\section{Introduction}

The principal animals to be used for study in this course will be the shark (Squalus acanthias), representing a rather primitive vertebrate; the mudpuppy (Necturus maculosus), an amphibian representing a stage in the transition of animals from aquatic life to land life; and the cat (Felis domestica), a typical land mammal. From time to time reference will be made to demonstrations of other animals. A more ideal arrangement would be to study representatives of all groups of vertebrates, but in a one-semester course time does not permit. However, the instructor will supply additional material for those who wish to do extra work.

In as much as one aim of the course is to present anatomy from the standpoint of evolution, all organ systems will be studied in a comparative way. The order of procedure will be to study the same organ system in each vertebrate before taking up the next organ system.

Do not lose sight of the function of an organ. That the anatomy of an organ is correlated with its function is a fundamental principle in zoology and should be kept in mind. As you dissect try to imagine how the various parts would act in a living animal.

The descriptions are based on average normal animals, but many variations occur. Do not attempt to make the specimen fit the description. Conduct dissections in the spirit of investigation. Try to find things for yourself before asking for help. Of the three ways of acquiring knowledge-observation, discussion, and reading-observation is the most important in anatomy. Those who can see only what is pointed out to them do not make good scientists.

Form the habit from the beginning of looking up the meaning and pronunciation of words you do not know. Also, look up the derivation of technical terms; it will help in remembering them. 
The outline is not divided into two-hour studies; the work is continuous. Do as much as you have time for in one period; at the next period review briefly the previous day's accomplishment and then go on with new work. The materials used in this course are expensive and care must be exercised in using them. Report damaged skeletons and demonstration specimens immediately. Dissection materials must be kept in their proper containers when not in use. Do not expect the instructor to look after your specimens for you.

The keeping of a notebook for recording observations in the laboratory is expected. One of the best ways of learning the details of anatomy is to make outline drawings and label them completely. It is essential, of course, that one think about the subject while executing the drawing. Drawings should be made on good quality paper. It is immaterial as to the size of the paper selected or whether you prefer a loose leaf system or a bound book, but be consistent. A list of the drawings required will be posted in the laboratory. This is the minimum requirement. Your instructor will be glad to correct any additional drawings you may wish to make.

A thorough knowledge of the work covered in the laboratory and of the functions of the various structures is expected. Examinations, oral, written or both, will be given from time to time. The quality of your dissections is important. Each student is expected to make his own dissections. Sponging on another is a sign of lack of ability or of mental laziness. Have all dissections checked by the instructor at the time they are made and before organs are removed. 


\section{BRIEF SURVEY OF THE VERTEBRATES}

Much of the work included in this section will be a review for those who have had a course in General Zoology. However, it is important as a preface to the work which comes later. A knowledge of the general classification of the vertebrates is expected. The following brief outline of the phylum Chordata is included for purposes of reference.

\section{PHYLUM CHORDATA}

Sub-phyla: I. HEMICHORDA-acorn worms

II. UROCHORDA-sea squirts

III. CEPHALOCHORDA-amphioxus

IV. vertebrata-fishes, frogs, reptiles, birds, mammals

\section{Classes of Vertebrata}

I. Cyclostomata-lamprey

2. Elasmobranchil-sharks, rays

3. Pisces-fishes

Crossopterygii-fossil fishes related to ganoids

Dipnoi-lung fishes

Ganoidei-ganoid fishes: garpike, sturgeon

Teleostei-common bony fishes: perch, trout

4. Amphibia-salamanders, frogs, toads

Stegocephala-a group of fossil amphibians

Caudata-tailed amphibians: salamanders

Salientia-tailless amphibians: frogs, toads

5. Reptilia - lizards, snakes, turtles, alligators

Thermomorpha-a group of fossil reptiles

Squamata-lizards, snakes

Testudinata-turtles

Crocodilia-crocodiles, alligators

6. Aves-birds

7. Mammalia - mammals 


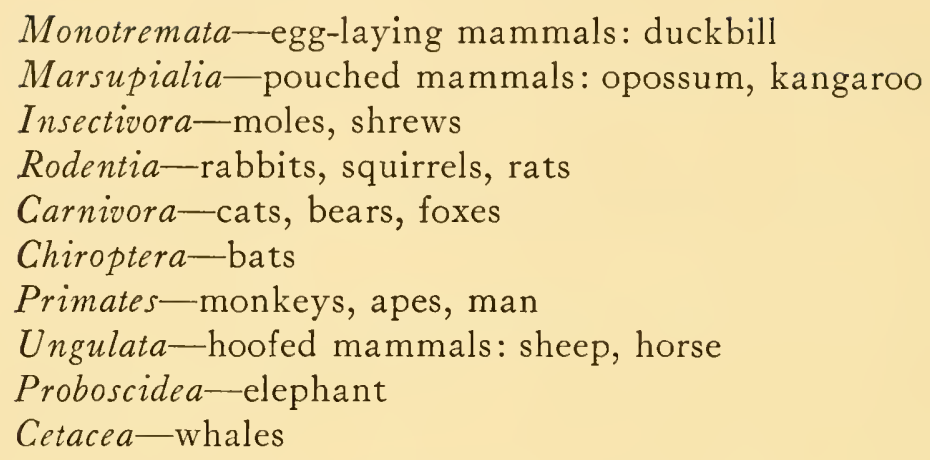

\section{Amphioxus-A Primitive Chordate}

Although amphioxus is not a vertebrate, it is of great importance in a study of comparative anatomy for it contains vertebrate structures in a simplified condition and is by many biologists thought to be similar to the ancestors of the vertebrates. A knowledge of the anatomy of amphioxus will aid greatly in understanding the origin of many vertebrate organs.

Examine specimens of amphioxus that have been stained. The pointed end is posterior. The head is poorly developed, possibly degenerate. The expanded membrane at the anterior end is the oral hood, which forms a cavity, the stomadaeum, within. The mouth lies at the bottom of the cavity. The oral hood is fringed with cirri or tentacles. A dorsal fin extends along the back and continues around the posterior end as the caudal fin. The two folds on the ventral side are the metapleural folds. These will be mentioned again in connection with the evolution of paired appendages. The metapleural folds meet at the atriopore, a depression on the ventral side serving as an outlet for water used in respiration. The anus is near the posterior end on the left side. The V-shaped muscle plates on the sides are called myomeres. These are separated by sheets of connective tissue known as myocommata (singular, myocomma). Along either side may be seen the numerous gonads, segmentally arranged.

The internal structures can perhaps be studied best by examining cleared mounted specimens and models and charts. The mouth opens into the pharynx, a wide cavity extending posteriorly into the straight intestine. The pharynx is per- 
forated by numerous gill slits. In respiration water passes through the gill slits into a large cavity, the atrium, which connects with the atriopore. The skeletal structures supporting the gills are the branchial bars. The liver is a simple unbranched diverticulum on the ventral side of the intestine. Dorsal to the intestine lies the notochord, and just above this, the nerve cord.

Study cross sections of amphioxus cut through different regions of the body. The outer covering, the epidermis, is composed of a single layer of cells. The dermis, beneath the epidermis, is a thin layer of connective tissue. Identify the myomeres, the thick masses of muscle; notochord; nerve cord; dorsal fin ray, a connective tissue support for the dorsal fin; pharynx with its gill slits and branchial bars in sections of the anterior end; atrium; intestine and liver, in sections behind the pharynx; metapleural folds. The ciliated groove on the ventral side of the pharynx is the endostyle, a structure often considered as the evolutionary forerunner of the thyroid gland.

\section{Lamprey-Class Cyclostomata}

Examine whole and dissected lampreys. There are two dorsal fins and a caudal fin, but paired appendages are absent. The skin is soft and slimy and contains numerous glands. True jaws are missing. The large cavity on the ventral side of the head, lined with horny teeth, is the buccal funnel. The tongue, also covered with horny teeth, lies at the bottom of the funnel. There is but one nostril, on the dorsal side of the head. The eyes are indistinct. Posterior to the eye, on each side, is a row of seven gill slits. The anus opens on the ventral side near the caudal fin. Close behind the anus is the urogenital aperature.

In a median sagittal section locate the tongue and its large retractor muscles; the pharynx and gill slits; the muscular heart; the large notochord and above it the small brain and spinal cord; the thin ribbon-like intestine; the liver, close behind the heart; and further back, the kidneys and gonads suspended from the dorsal body wall.

Identify these same structures in cross sections of lampreys cut at various levels. Under the notochord are three blood vessels, a median aorta and two lateral cardinal veins. 
Although considered a vertebrate, the lamprey has very rudimentary vertebrae which consist merely of minute cartilages on either side of the notochord.

\section{Shark-Class Elasmobranchit}

The elasmobranchs are the cartilaginous fishes. By some they are classified as belonging to an order of Pisces; others think they are sufficiently diverse to form a separate class by themselves.

The mouth is ventral in position. At each corner is an oronasal groove, extending toward, but not reaching the nostril. The sharply pointed teeth are arranged in several rows. They are really modified scales.

The nares or nostrils on the ventral side of the head are mere pits and have no connection with the mouth. The opening of each nostril is wholly or partly divided by a projecting flap of skin.

The eyelids are not movable. Behind the eyes are a pair of spiracles. These are modified gill slits and contain small gills. Do they open into the mouth cavity? There are five gill slits on each side, each with its own gill cover. Do the gill slits connect with the mouth cavity?

The cloaca is a small cavity on the ventral side about twothirds the way back toward the tail. It is the common outlet of both digestive and urogenital systems. Within it is the urogenital papilla with the urogenital pore at its tip.

The fins consist of two dorsal fins, a caudal fin, paired pectoral fins, and paired pelvic fins. An anal fin just posterior to the cloaca is present in most fishes, but is absent in this species of shark. Male elasmobranchs may be distinguished from females by the presence in males of a clasper on the inner margin of each pelvic fin.

A sense organ, the lateral line, extends as a shallow groove along each side of the body. On the dorsal side of the head are numerous small pores which are part of the lateral line system. On the ventral side of the head are similar pores not directly connected with the lateral line organs. These are the ampullae of Lorenzini and are probably sensory in function. Do they 
have a definite arrangement? By pressing on the skin a jellylike substance can be forced out.

On the top of the head, between the spiracles, are the openings of two small endolymph ducts, which connect with the ears. These will be mentioned again in the study of the skull and the sense organs.

The body is covered with small placoid scales, which can best be located by running a finger over the skin from the tail toward the head. Examine a demonstration of them under the microscope. They are of special interest because of their homology with vertebrate teeth.

\section{Garpike-Class Pisces}

The body is covered with ganoid scales, a peculiar type of scale found also on many fossil fishes. In fact, the ganoid fishes are related to the group of fossil fishes from which the land vertebrates are thought to have arisen. What fins are present? Is the mouth ventral in position as in the shark? A gill-cover, the operculum, covers the gills. A spiracle is absent.

\section{Bony Fishes-Class Pisces}

Bony fishes of several different types should be compared with the garpike. Observe particularly the absence of the heavily armored condition, the position of the pelvic fins, and the type of scale. The ctenoid scales are bony plates derived from the dermis of the skin and are set in pockets. Examine a scale under the microscope. Are the small teeth on the proximal or on the distal edge? The concentric rings are lines of growth. With training the age of a fish may be told, with a fair degree of accuracy, by the condition of the lines of growth. Are the pelvic fins at the posterior end of the body in all fishes? The teleosts are of more recent evolutionary origin than are the other groups of fishes.

\section{Necturus-Class Amphibia}

Although aquatic this amphibian possesses many characteristics of land vertebrates. The skin is scaleless, soft, and slimy, and contains many glands. If you are not already 
familiar with the structure of the amphibian skin examine a demonstration slide. Distinguish between the outer epidermis and the deeper dermis. The glands, although derived from the epidermis, lie wholly within the dermis.

The nostrils communicate with the mouth cavity. Compare with the shark in this respect. The three pairs of external gills do not correspond to the internal gills of fishes. Gill slits (how many?) are present and open into the pharynx. Water, however, contrary to the condition in fishes, does not ordinarily pass through the slits during respiration. Watch the respiratory movements of the external gills of a living Necturus if one is available. The paired appendages, although consisting of arms and legs with digits on the hands and feet, correspond to the fins of fishes. Claws are absent. Find the cloaca at the junction between body and tail.

\section{Lizard-Class Reptilia}

Lizards are closely related to snakes and belong to the same order. Their horny scales are derived from the epidermis and thus are not homologous to the bony scales of fishes. The presence of a dry scaly skin is characteristic of reptiles; there are very few skin glands. Claws are present on the digits. The nostrils, as in amphibians, open by internal nares in to the mouth cavity. There are three eye-lids: an upper, a lower, and a nictitating membrane (a thin membrane lying in the inner corner of the eye when not in use). The depression in the skin behind the eye may be considered as the beginning of an external ear. The tympanic membrane stretches across the bottom of the depression, covering the cavity of the middle ear. Fishes and Necturus possess internal ears only. The comparative anatomy of the ear will be discussed later.

\section{Turtle-Class Reptilia}

The shell, which consists of a dorsal carapace and a ventral plastron, is made up of bony scutes covered with epidermal scales. Are the scales of the same size and shape as the scutes beneath? Teeth are absent; the jaws are covered with a horny epidermis. 
Bird-Class Aves

The chief distinguishing character of birds is the presence of feathers, which are found nowhere else in the animal kingdom. Examine also the horny beak, the fore-limb modified for flying, and the scales on the legs. The scales are homologous to the scales of reptiles. As in reptiles, skin glands are restricted in number and distribution.

\section{Cat-Class Mammalia}

The cat is so familiar that a detailed study of its external anatomy is not necessary. However, examine a specimen as opportunity arises and observe particularly the following:

I. The vibrissae or tactile hairs on upper lips, cheeks, and above the eyes.

2. The absence of hairs in certain regions of the body.

3. The retractile claws.

4. The soft pads on the soles of the feet.

5. The remnant of the nictitating membrane. 


\section{THE SKELETAL SYSTEM}

As the skeleton largely determines the general form of the body and as locomotion and means of getting food are conditioned by its structure, a study of the skeletal system should reveal some interesting phases of comparative anatomy.

For convenience the vertebrate skeleton may be divided as follows:

Axial skeleton

Skull

Cranium (neurocranium)

Visceral skeleton (splanchnocranium)

Vertebral column

Ribs

Sternum

Appendicular skeleton

Pectoral girdle and fore limbs

Pelvic girdle and hind limbs

\section{Axial Skeleton}

\section{VERTEBRAL COLUMN, STERNUM AND RIBS}

All members of the phylum Chordata at some time during life possess a notochord. In most vertebrates this skeletal rod is replaced in later life by a series of bones, the vertebrae, closely articulated with one another, and forming the vertebral column or backbone. The presence of this vertebral column is one of the most distinguishing features of the vertebrates. Within the chain of vertebrae lies the neural canal, containing the spinal cord.

\section{Vertebral Column and Ribs of the Shark}

The division of the vertebral column into regions is largely, though not wholly, dependent upon the presence of limbs. In forms where limbs are lacking (e.g., snake), and in animals that do not depend on the limbs for support, as in many aquatic 
species, the divisions of the vertebral column are not very marked. In the shark there are only two regions, body and caudal.

Body Vertebrae.-Use a prepared specimen consisting of several vertebrae. The vertebrae of the shark are comparatively simple in structure, composed largely of cartilage with some deposition of lime, but have no real bone formation. The more or less cylindrical basal portion of each vertebra is the centrum or body. Above this is the neural arch forming a roof over the neural canal, which serves for the passage of the spinal cord. The centra are amphicoelus; that is, they are concave on each end. At the bottom of each concavity is a small canal which leads through the centrum to the concavity on the other end of the vertebra. The continuous space thus formed is occupied by the remains of the notochord. On the ventral side of each centrum transverse processes extend laterally. Attached to each of these, during life, is a slender rib. The ribs are usually absent on the separate preparations of vertebrae, but may be seen on the mounted skeletons. The neural arches over the central canal are composed of alternating neural processes and interneural plates. These are roughly triangular in shape. Each neural process has its base resting on the centrum; the interneural plates fill in the spaces between successive neural processes. The interneural plates of each side unite dorsally; the neural processes may or may not. A foramen for the exit of the ventral root of a spinal nerve lies in each neural process; a foramen for the exit of the dorsal root in each interneural plate.

Caudal Vertebrae.-The centra, neural processes and interneural plates are similar to those of body vertebrae. A haemal arch, which protects the large blood vessels of the tail, lies ventral to the centrum. There are no transverse processes and no ribs.

\section{Vertebral Column, Sternum and Ribs of Necturus}

Study the specimens mounted in glass jars. The vertebral column consists of three regions: cervical (one vertebra), body, and caudal. There is little differentiation of the vertebrae. In the caudal region haemal arches are present. A single 
vertebra supports the pelvic girdle. The vertebrae articulate with one another by over-lapping processes, a condition characteristic of land vertebrates. The centra are amphicoelus as in the shark.

A sternum, if it may be called such, is represented by a few cartilages on the ventral side.

The short triangular ribs have two heads, a dorsal tuberculum and a ventral capitulum, for articulation with the transverse processes of the vertebrae.

Vertebral Column, Sternum and Ribs of the Alligator

The vertebral column is differentiated into the five regions characteristic of mammals. There are nine cervical, bearing ribs; ten thoracic, bearing long ribs which reach the mid-ventral line; five lumbar; two sacral; and numerous caudal vertebrae. The sacral vertebrae bear short stout sacral ribs for the support of the pelvic girdle. Haemal arches are present on some of the caudal vertebrae. Toward the end of the tail, however, the various processes have become so reduced that practically only the centra remain. Alligator vertebrae are procoelus (centra are concave anteriorly, convex posteriorly).

A sternum is present between the two halves of the pectoral girdle. It is drawn out posteriorly into long curved cartilages.

Observe the manner of attachment of the ribs. Are tuberculum and capitulum present as in Necturus? Costal (rib) cartilages make their first appearance in reptiles.

\section{Vertebral Column of the Cat}

In the vertebral column of the cat there are five regions:

(I) Cervical vertebrae, seven in number and forming the skeleton of the neck.

(2) Thoracic or costal vertebrae, thirteen, bearing ribs.

(3) Lumbar vertebrae, seven, without ribs.

(4) Sacral vertebrae, three fused in to one mass and supporting the pelvic girdle.

(5) Caudal vertebrae, about twenty-three forming the skeleton of the tail in ordinary cats, but only four or five in the short-tailed Manx cats.

Thoracic Vertebrae.-All vertebrae are built on the same general plan, but there are many kinds of modifications. 
Examine a fourth or fifth thoracic vertebra. Assuming it to be a typical vertebra, study it in detail; and then compare it with the vertebrae of other regions.

Centrum.-This is the solid body of the vertebra, ventral to the neural canal. Each centrum articulates with centra of adjacent vertebrae. The smooth ends of the centrum (as on other bones) are the epiphyses. In kittens the epiphyses are easily pulled off, but in adult cats they are often so completely fused to the rest of the centrum that they are not readily distinguishable. The centrum is acoelus, meaning that its ends are not hollowed out to form cavities. On the caudal surface, at the dorsal-lateral corner on each side, find a small smooth area bounded by a ridge of bone. These are costal demifacets. Similar costal demifacets, not bounded by bony ridges, are to be found on the cranial end of the centrum. The posterior demifacet of one vertebra and the anterior demifacet of the succeeding vertebra form the surface for the articulation of the head of a rib.

Neural Arch.-This is the bony arch above the centrum. It is continued dorsally into a long neural spine. The cavity beneath the arch is the neural canal, which during life contains the spinal cord. Between the arch and the centrum on the posterior end is a notch, the intervertebral foramen, for the exit of a spinal nerve. From the neural arch on each side extends laterally a short transverse process, which bears on the ventral face of its distal end a smooth tubercular facet for articulation with the tubercule of a rib. On the cranial border of the neural arch, between the transverse processes, are two slight projections, the prezygapophyses (cranial articular processes), each with a smooth dorsal face, the cranial articular facet. On the caudal border, at the base of the neural spine, are similar postzygapophyses (caudal articular processes), but with the caudal articular facets facing ventrally. What is the relation of the caudal facets to the cranial facets?

Examine the other thoracic vertebrae in a mounted skeleton, and see how they differ in detail from the one studied.

After studying a thoracic vertebra to serve as a type, compare vertebrae from other regions with it.

AtLas.-This is the first cervical vertebra. The centrum has been appropriated by the second vertebra; its place is taken 
by a narrow ventral arch. The transverse processes are large and wing-like, and are pierced near the base by foramina transversaria for passage of the vertebral artery. The cranial articular processes for receiving the occipital condyles of the skull are large. Dorsal to them lie the atlantal foramina for the continuation of the vertebral artery. The caudal articular facets articulate with the second vertebra.

Axis.-This is the second cervical vertebra. The projection at the anterior end of its centrum is the odontoid process (odontoid, toothlike), which is really the centrum of the atlas. Observe particularly: the small transverse processes, the foramina transversaria, the large cranial articular facets, the neural spine, and the caudal articular facets.

Cervical Vertebrae.-Notice the gradual transition in them. On some the transverse processes arise by two roots, one from the centrum and one from the arch. Between the two lies the foramen transversarium for the vertebral artery. The transverse process divides distally into a dorsal projection representing the transverse process proper, and a ventral costal process representing a rib. Observe differences between different cervical vertebrae in this respect.

Lumbar Vertebrae.-These are larger than the thoracic, the transverse processes are more complicated in structure, the spinous processes are shorter, and there are no ribs.

Sacral Vertebrae.-These, usually three in number in the cat, are united in the adult into a single bone, the sacrum. What evidence is there of the multiple character of the sacrum?

Caudal Vertebrae.-These gradually decrease in size, becoming longer and more slender, and finally are reduced to mere centra. In life several of the caudal vertebrae, after the third, bear haemal processes tipped by chevron bones to form a haemal canal. The chevron bones are usually lost in preparing the skeleton.

Examine a cervical vertebra of a horse. Is the centrum procoelus or opisthocoelus (convex anteriorly, concave posteriorly)?

\section{Sternum of the Cat}

Locate the sternum or breast bone on a mounted skeleton. It is made up of eight pieces, called sternebrae, distributed over threc regions as follows: 
I. The manubrium or presternum, the arrow-shaped anterior piece.

2. The mesosternum, made up of six sternebrae.

3. The xiphisternum (xiphos, sword) or metasternum, the long posterior piece. It ends in a fan-shaped xiphoid cartilage, which becomes much shriveled on dry skeletons.

\section{Ribs of the Cat}

A typical rib, the fifth or sixth, should be studied. It consists of the following parts:

I. A head or capitulum, the end of which articulates with the centra of two thoracic vertebrae at the costal demifacets.

2. A tubercule or tuberculum, a slight projection close to the head, for articulation with the transverse process.

3. The neck, the short portion between head and tubercle.

4. The shaft, the long portion between the tubercle and the costal cartilage. The point of sudden turn in this portion is the angle.

5. The costal cartilage, the cartilaginous connection between the ventral end of the shaft and the sternum.

Various mammals have from nine to twenty pairs of ribs. Distinguish differences between the various pairs in the cat. Those ribs that connect by their own cartilages to the sternum are known as true ribs, the rest as false ribs. There are normally nine pairs of true and four pairs of false ribs in the cat. The first three pairs of false ribs have cartilages uniting with the cartilages of the last true ribs. The last pair of ribs have no such cartilages and are known as floating ribs.

\section{SKULL}

Skulls occur only in vertebrate animals. In the simpler species it is convenient to consider the skull as consisting of two parts: (I) cranium (neurocranium) which surrounds and protects the brain, and (2) visceral skeleton (splanchnocranium) which forms the jaws and gill arches where these are present. In higher vertebrates parts of the visceral skeleton are transformed to serve other purposes.

\section{Cranium of the Shark}

On a mounted skeleton identify the cranium and visceral skeleton. Observe that the visceral skeleton is not a part of 
the cranium and is held to it merely by ligaments. Secure a separate cranium for detailed study. Shark crania are fragile and expensive. They must be handled with great care and must be kept in their containers when not in use. Do not allow them to become dry.

Observe that the whole cranium forms one continuous cartilaginous mass. This is known as a chondrocranium. Although the cartilage is sometimes strengthened by impregnation of lime, there is no real bone formation in any part of the shark skeleton.

Find the following outstanding features:

I. Orbits (eye sockets).- - The lateral projections in front of the orbits are the anterior orbital processes; those behind the orbits are the posterior orbital processes. Between these two processes and forming a shelf above each orbit is the supraorbital crest.

2. Rostrum.-This is the scoop-like projection at the anterior end of the cranium, opening dorsally. The open cavity of the rostrum is the anterior fontanelle, which in life is filled with a gelatinous substance. Normally the rostrum is braced by rostal bars, extending from its tip to the anterior orbital processes, but in prepared crania these bars are usually missing. On the ventral side of the rostrum is a keel.

3. Foramen Magnum, a large opening at the posterior end of the cranium for the exit of the spinal cord.

4. Occipital Condyles, small projections, one on either side of the foramen magnum, for articulation with the first vertebra.

5. Endolymphatic Fossa.--This fossa is the large depression on the dorsal surface anterior to the foramen magnum. Within it are two pairs of openings: the anterior smaller ones are the openings of the endolymphatic ducts; the posterior ones, the openings of the perilymphatic ducts. These ducts connect with the internal ears, which lie embedded in the cartilage of the otic region.

6. Otic Region (ear region).-Extending anteriorly on each side of the endolymphatic fossa are ridges which indicate the location of the anterior semicircular canals. Similar ridges extending posteriorly mark the position of the posterior semi- 
circular canals. The position of the horizontal semicircular canal is indicated by a ridge on the lateral side of the cranium between the posterior orbital process and the post-otic process. The post-otic process forms the posterior-lateral corner of the cranium. What is the function of the semicircular canals? They will be dissected when the sense organs are studied.

7. Fenestrae.-These are the large openings on the ventral surface, one on either side of the keel of the rostrum. In life they are closed by membranes.

8. Olfactory Capsules. - These large openings on the anterior end of the cranium, lateral to the fenestrae, are for the organs of smell. During life they are closed, but the thin anterior walls are usually destroyed in preparation of the cranium.

9. Principal Foramina.-The large hole through the median wall of each orbit is the optic foramen, for passage of the optic nerve. In the posterior ventral corner of the orbit is a group of five foramina, the largest of which is for the exit of the fifth and seventh cranial nerves; the others are for the third and sixth nerves and for blood vessels. The row of foramina extending along either side of the dorsal surface is for passage of branches of the fifth and seventh nerves. The small foramen posterior to the anterior fontanelle marks the location of the epiphysis, a small dorsal outgrowth of the brain. On the posterior end of the cranium are four large foramina; the lateral ones are for the exit of the ninth cranial nerves, the medial ones for the passage of the tenth cranial nerves. The foramen in the mid-ventral line, behind the orbits, is for the entrance of the internal cartoid arteries.

Examine a cranium that has been bisected longitudinally. Identify the structures previously mentioned, and in addition locate the foramen for the passage of the eighth nerve to the ear, the cavity for the brain, and the depression on the floor of the cranium in which the pituitary gland rests.

\section{Visceral Skeleton of the Shark}

For this study use the mounted skeletons. A knowledge of the visceral arches of the shark is essential for a clear understanding of the modifications that occur in higher vertebrates. 
In this species of shark there are seven cartilaginous arches nearly surrounding the anterior part of the alimentary canal and supporting its walls. The first two visceral arches are in close connection with the cranium. The details of structure of the visceral skeleton are difficult to study on mounted skeletons, but with the aid of a chart and the following description make out as much of the anatomy as possible.

I. Mandibular Arch.-Both upper and lower jaws are derived from the first visceral arch. The upper jaw is a strong bar of cartilage formed by the union of paired pterygo-quadrate cartilages meeting in the median line. The lower jaw is made up wholly of Meckel's cartilage.

2. Hyord Arch.-This, the second visceral arch, lies immediately posterior to the lower jaw. Its ventral half forms the hyoid apparatus supporting the floor of the mouth. The dorsal half connects the hyoid apparatus and both jaws to the cranium. The hyoid consists of five cartilages: a single mid-ventral basihyal; two ceratohyals which are attached to the ends of the basihyal and extend parallel to the lower jaw; and two hyomandibular cartilages attached to the corners of the cranium above and supporting both jaws. The ceratohyals and hyomandibulars bear gill rays, slender cartilaginous rods which support the first gill cover.

3. Gill Arches.-There are five arches which support the soft structures of the gills. Theoretically each gill arch should contain nine separate cartilages, but this ideal arrangement is never retained by all of the arches.

Read up on the evolution of the visceral skeleton.

\section{Skull of a Ganoid Fish}

Examine the head of a gar-pike or other ganoid fish. The ganoids show considerable advance over the elasmobranchs in the development of the skull. Large dermal scales cover the chondrocranium and form the roof and sides of the cranium. As some of these large scales correspond to the superficial bones of higher vertebrates, they have received the same names. The pterygo-quadrate cartilage of the upper jaw and Meckel's cartilage of the lower jaw have also become encased with dermal scales, which form the superficial bones of the jaws. 
The upper jaw, unlike that of the shark, is inseparably fused with the cranium and must be considered as part of it. Because of their manner of origin from the dermis, the superficial bones of the cranium and jaws are known as dermal, membrane, or investing bones. Remember that the dermal bones are on the outside, embedded in the skin, and that a typical cartilaginous skull is present inside the covering of scales.

A study of the individual bones will not be attempted. Notice, however, that they are very numerous. Development of membrane bones was greatest in the earliest amphibians and reptiles, but in living land vertebrates the number has been greatly reduced through loss and fusion.

\section{Skull of an Amphibian}

The descriptions are written for Necturus, but with slight modifications may be applied to Cryptobranchus, an aquatic amphibian somewhat similar to Necturus but much larger. Examine both a dry skull and a specially prepared chondrocranium of Necturus. Necturus, like the fishes, has in reality two skulls, a partially ossified chondrocranium on which is superimposed a roof of membrane bone. Identify the foramen magnum and the two occipital condyles. The fine lines at the points of articulation between bones are known as sutures. The upper jaw consists of three bones bearing teeth. Beginning anteriorly these are the premaxillary, the vomer, and the palatopterygoid. The large, unpaired bone forming most of the floor of the cranium is the parasphenoid. On the dorsal side, forming the roof of the cranium, are the paired frontals, articulating with the premaxillaries anteriorly, and posterior to these, the parietals. On either side of the foramen magnum is an exoccipital bone, each with its occipital condyle for articulation with the first vertebra. The otic capsules are partially ossified; the opisthotic bones lie lateral to the exoccipitals and help form the posterior corners of the skull, while the prootics are the small bones in the anterior part of the otic region. Extending obliquely forward from the opisthotic is the slender squamosal bone. Beneath this and articulating with the lower jaw is the quadrate. This bone represents an ossified remnant of the pterygo-quadrate cartilage of the shark. The cartilage bones 
of the Necturus skull, namely, exoccipital, prootic, opisthotic, and quadrate, are best seen in the chondrocranium preparations.

The lower jaw consists of membrane bones surrounding Meckel's cartilage. The dentary bone, bearing teeth, constitutes the outer surface of each half of the jaw. The inner surface is composed of two bones, the splenial and the angular, the latter forming the extreme posterior end of jaw below the dentary. In Cryptobranchus ossification of a portion of Meckel's cartilage to form the articulating surfaces of the jaws has begun. This bone is the articular; it articulates with the quadrate bone of the upper jaw.

Examine the visceral arches on a mounted skeleton of Necturus. The hyoid arch is the bar of cartilage parallel and posterior to the lower jaw. The three gill arches are remnants of the third, fourth and fifth visceral arches. As compared to the shark the gill arches are not only reduced in number but also in the cartilages composing them.

\section{SkUll of the Alligator}

The skull of the alligator is almost completely ossified, the chondrocanium having been replaced by bone. Although the alligator skull will not be studied in detail, the following features should be noted: (I) There are more bones present than in mammal skulls. (2) There is but one occipital condyle. (3) There are no teeth on the roof of the mouth as in Necturus, Cryptobranchus, and many fishes; teeth are borne on the maxillary, pre-maxillary, and dentary bones only. (4) The quadrate bone, an ossified remnant of the pterygo-quadrate cartilage, forms the articulation with the lower jaw. (5) The lower jaw consists of two halves or rami united in front by a symphysis. The bones of each half are: the dentary, bearing teeth and forming the outer two-thirds of each jaw; the splenial, forming a large part of the inner side; the angular, below the large mandibular foramen; the sur-angular above the foramen; the coronoid, a small bone on the inner surface forming part of the anterior boundary of the mandibular foramen; and the articular, which contains a concavity for articulation with the quadrate of the upper jaw. The articular is an ossified portion of Meckel's cartilage. A remnant of Meckel's cartilage still 
remains as a core within each ramus. What has become of the gill arches in the reptiles?

\section{Skulli, of The CAT}

In the cat, as in all mammals, bone has replaced cartilage almost entirely, at least in adults. There is also a tendency for bones to unite with one another so that the mammalian skull contains fewer bones than a similar skull of its amphibian or reptilian ancestors. The following features serve as landmarks:

Orbits (eye sockets).-Are they completely surrounded by bone? Compare with the skulls of other mammals in this respect.

Temporal fossa (fossa, ditch), a space just behind the orbit into which a projection from the lower jaw extends.

Zygomatic arch (zyge, yoke), the bar of bone ventral to the orbit and temporal fossa.

Foramen magnum, the large hole at the posterior end of the skull through which the spinal cord passes to the brain.

Occipital condyles, bony projections on either side of the foramen magnum for the articulation of the skull with the first vertebra.

Nares, the nostrils.

Lambdoidal ridge (from Lambda, the Greek letter L), an arched ridge of bone extending transversely dorsal to the foramen magnum.

Sagittal crest (sagitta, arrow), a ridge extending anteriorly from the center of the lambdoidal ridge. Both the lambdoidal ridge and the sagittal crest are inconspicuous or absent in kitten skulls.

Tympanic bullae (bulla, bubble), paired swellings on the ventral side of the skull, anterior to the occipital condyles. Each contains the bones and sensory part of the ear.

External auditory meatus (meatus, passage), the opening on the lateral side of each tympanic bulla.

Choanae (choana, funnel), posterior openings of the nasal passages on the ventral side of the skull.

The bones of the skull will be described in order, as far as possible, beginning at the posterior end. Each bone should be 
located on the skull and its boundaries traced. The fine lines of separation between bones are known as sutures. Be prepared to demonstrate the articulations of each bone with the others. Examine also specimens of the separate skull bones. The separate skull bones are not to be removed from the laboratory at any time. Do not mark on the bones. Use a needle or metal probe in tracing sutures; never a pencil.

I. Occipital.- This bone surrounds the foramen magnum and forms practically the whole of the posterior face of the skull. It really represents four bones ( 1 basi-, 2 ex-, and $\mathbf{r}$ supraoccipital) which remain separate in many lower vertebrates, and are separate also in young mammals. The inner surface shows depressions corresponding to convolutions of the cerebellum of the brain. On the ventral surface of the skull the occipital extends anteriorly between the auditory bullae and meets the sphenoid bone. The condyles of the occipital, for articulation of the skull with the first vertebra, have already been mentioned.

2. Parietals.-The paired parietals, meeting in the median line, form the posterior half of the roof of the cranium. They extend far down on the sides. The shelf or tentorium on the inner surface extends down between cerebrum and cerebellum of the brain and articulates with the sphenoid, a fact not easily observed in a whole skull.

3. Interparietal.-This small, median, triangular bone extends anteriorly from the dorsal edge of the occipital as a wedge between the posterior parts of the parietals. In old cats it is usually fused completely with the parietals or occipital, and is then not a distinct and separate bone.

4. Frontals.- Paired frontals, meeting in the median line and lying immediately anterior to the parietals, form the remaining portion of the roof of the skull and a large part of the medial wall of the orbit. From the dorsal-lateral part of the frontal posterior to the orbit, extends the zygomatic (postorbital) process. It extends ventrally toward a similar process of the malar bone, and may articulate with it. Looking at a separate frontal bone from its anterior end discloses an opening into a cavity within the bone. This is the frontal sinus, which in life is connected with the nasal cavity. 
5. Nasals. - The two nasals meet in the median line and extend from the frontals to the nares.

6. Premaxillaries.-These are paired bones forming with the nasals the borders of the nasal opening. They form the anterior portion of the upper jaw and bear on each side three incisor teeth.

7. Maxillaries. - The paired maxillary bones form the remainder of the upper jaw on each side, and the anterior and lateral portions of the roof of the mouth. Each bears one canine tooth, three premolars, and one molar. The maxillaries extend dorsally to meet the nasals and frontals and the median surface of each maxillary forms a large part of the lateral wall of the nasal cavity. Dorsal to the premolars the maxillary has a projection, the malar process or zygomatic process for articulation with the malar bone. The large hole in the maxillary is the infra-orbital foramen for passage of a nerve and a blood vessel.

8. Malars.-The malars are paired. Each extends posteriorly from the malar process of the maxillary bone and forms the major portion of the zygomatic arch. Each overlaps and articulates with the zygomatic process of the temporal bone. A post-orbital process extends toward and frequently unites with the similar process of the frontal.

9. Lachrymals.- These thin bony plates in the anterior wall of each orbit frequently fall out in dry skulls. On the anterior border of each is the opening of the lachrymal canal (tear duct), which connects with the nasal cavity.

Io. Temporals. - The temporals are also paired, lying ventral to the lateral borders of the parietals, and forming a large part of the lateral wall of the cranium posterior to the orbit. The temporal bone of mammals represents a fusion of a number of bones which are separate in lower forms. The resulting complicated structure is conveniently divided into four regions, corresponding in a general way to the parts from which the temporal has developed: the squamous, the mastoid, the petrous, and the tympanic.

The squamous region is the thin plate adjoining the parietal. Anteriorly it gives off a long zygomatic process, which joins the malar and forms the posterior portion of the zygomatic arch. On the ventral surface of this process, near its base, is the 
mandibular fossa, a notch for the articulation of the mandible.

The tympanic region consists of the tympanic bulla ventrally (already mentioned), and the ring of bone surrounding the external auditory meatus.

The mastoid region includes the heavy, thickened portion posterior to the external auditory meatus. It lies between the squamous region and the bulla.

The petrous region is seen best on the inner surface of the temporal bone. From this side it is the central mass of very dense bone (hence the name, meaning stony) between the squamous region and the tympanic bulla. In it are embedded the structures of the inner ear.

Turn now to the ventral surface of the skull and again locate the premaxillaries and the maxillaries. Then look for the following:

II. Palatines.-The two palatines form that portion of the roof of the mouth behind the maxillaries. Each palatine has a vertical plate, forming part of the wall between orbit and nasal cavity and extending posteriorly to meet processes of the sphenoid.

I 2. Vomer.--This is a single bone seen by looking into the anterior nares. It is a slender, elongated bone in the floor of the nasal cavity, and has a groove on its dorsal surface. At its posterior end it articulates with the body of the presphenoid. Only this posterior end is visible on the ventral surface.

I3. Presphenoid.-This bone is made up of two portions, which are distinct in young kittens and in lower vertebrates. These parts are the base (presphenoid of lower forms) and the two wings (orbitosphenoids). The base lies in the roof of the mouth just posterior to the vomers and is partly covered by the vomer, the palatine, and the sphenoid bones, so that only a narrow central strip is visible. The two wings come from nearly the whole dorsal-lateral angles of the basal portion. They appear on the surface as part of the median walls of the orbits, ventral to the frontal bones and posterior to the palatines. They carry the optic foramina for passage of the optic nerves.

I4. Sphenoid.- In man this is joined with the presphenoid to form a single bone; in the cat, however, it is separate. It is formed by the union of five bones which are found in lower 
vertebrates: the basisphenoid and the paired pterygoids and alisphenoids.

In the adult cat the basisphenoid is on the ventral surface of the skull between presphenoid and occipital. It is shield shaped with the apex pointing forward. Its dorsal surface has a projection, the dorsum sellae. Immediately interior to this projection is a deep excavation, the sella turcia (meaning Turkish saddle), in which is lodged the pituitary gland.

The wings are thin plates attached by their median borders to the lateral surfaces of the basisphenoid. Each wing is composed of a pterygoid process, which extends forward on the roof of the mouth between the presphenoid and the palatine; and an alisphenoid process, which extends forward and dorsally, meeting presphenoid, frontal, parietal, and temporal.

I 5. Eтнmoid.- This is an unpaired much-coiled bone, partially visible on looking into the nares. Examination of a separate bone will show that it consists of several parts.

a. The cribriform plate (cribrum, sieve), is so called because of its many perforations for the passage of the olfactory nerves. It forms the dividing wall between brain cavity and nasal cavity.

b. The lamina perpendicularis (lamina, a thin sheet), extends anteriorly from the center of the cribriform plate and forms part of the septum between the nostrils.

c. The ethmoturbinates, a complicated mass of thin folded sheets of bone, nearly fill the nasal cavity. The turbinates are attached to the vomer, the nasal, and the maxillary bones.

16. Mandible (inferior maxillary).-This forms the lower jaw. It is made up of two halves immovably united at the median symphysis. Each side bears three incisor teeth, one canine, two premolars, and one molar. Between canine and premolars is a diastema (an open space between teeth).

On the posterior part of the median surface of each ramus of the mandible is the inferior dental foramen, carrying nerves and arteries which emerge again through the two mental foramina on the external surface just below the diastema.

Posteriorly the mandible is marked by six prominent features:

a. The coronoid fossa, a large fossa on the lateral surface for the insertion of the masseter muscle. 
b. The angular process, a small projection at the posteriorventral angle.

c. The inferior notch, just above the angular process.

d. The condyle for articulation with the mandibular fossa of the temporal bone.

e. The superior notch above the condyle.

f. The large coronoid process at the dorsal angle, which projects into the temporal fossa of the cranium.

17. Hyoid Bones.-The hyoid apparatus consists of a chain of slender bones on each side, serving to support the tongue and larynx. These bones are usually absent on ordinary skeletons; examine them on a special demonstration specimen.

I8. Principle Foramina.-Locate the following foramina, some of which have already been mentioned:

a. The infraorbital foramen passes through the maxillary bone just ventral to the anterior end of the malar. It carries part of the fifth cranial nerve and a blood vessel.

b. The incisor foramina are the two openings on the ventral surface immediately posterior to the incisor teeth for the passage of the nasal artery and part of the fifth nerve. What bones surround them?

c. The sphenopalatine foramen is the larger of the two openings in the palatine bone in the wall of the orbit. It carries the sphenopalatine artery and part of the fifth cranial nerve.

d. The posterior palatine foramen is the smaller opening in the palatine bone, slightly anterior and ventral to the sphenopalatine foramen, through which the palatine artery and a branch of the fifth nerve pass.

e. The olfactory foramina are the many perforations of the cribriform plate of the ethmoid bone.

f. The optic foramen is the most anterior of the four foramina in the posterior ventral corner of the orbit. In what bone does it lic? It carries the optic nerve and meningeal artery.

g. The orbital fissure, the second of the four foramina in the posterior ventral corner of the orbit, is bounded by the wings of the presphenoid and sphenoid bones. It carries the third, fourth, and sixth cranial nerves and part of the fifth.

h. The foramen rotundum, the third of the four foramina in the corner of the orbit, lies wholly within the sphenoid bone. It carries part of the fifth cranial nerve. 
i. The foramen ovale lies immediately posterior to the foramen rotundum. It also carries a branch of the fifth nerve.

j. The stylomastoid foramen is a small opening posterior to the external auditory meatus for the passage of the seventh cranial nerve. The shallow groove ventral to this foramen is for the attachment of the hyoid bone.

k. Eustachian tube. At the anterior end of the tympanic bulla is a foramen which connects with the cavity of the middle ear within the bulla. It serves for the passage of the Eustachian tube from the middle ear to the pharynx.

1. The jugular foramen is an opening near the posterior end of the bulla and serves for the passage of the ninth, tenth, and eleventh cranial nerves and the jugular vein.

$\mathrm{m}$. The hypoglossal canal may be seen by looking into the foramen magnum on either side. The canal makes its exit near the jugular foramen. It carries the twelfth cranial nerve.

n. Internal auditory meatus. Examination of the internal surface of a separate temporal bone reveals two prominent openings. The larger one, anterior to the petrous region, is for the passage of the Eustachian tube, already mentioned. The other, consisting of a deep pit in the center of the petrous region, is the internal auditory meatus. The seventh and eighth cranial nerves enter it. The seventh emerges through the stylomastoid foramen; the eighth (auditory) passes to the inner ear by means of several foramina in the bottom of the pit.

Examine a skull bisected longitudinally and one with the top of the cranium removed. Identify the various parts. Skulls of different mammals are available in the laboratory for those who wish to compare them with the cat.

LARYNx.-Study the model of the human larynx. The U-shaped structure at the top is the hyoid bone which serves as a support for the tongue. The largest cartilage of the larynx is the thyroid cartilage, which gives the shape to the voice box. From the notch in the anterior of the thyroid cartilage extends the epiglottis, which during the act of swallowing, covers over the opening into the larynx and prevents food entering. The two small cartilages to which one end of each vocal cord is attached are the arytenoids. The arytenoid cartilages rest on the cricoid cartilage, which is shaped somewhat like a signet ring. Changes in position of the cricoid and arytenoids with respect 
to each other and to the thyroid, produce, the changes in the tension on the vocal cords. The vocal cords are elastic tissue covered over with a mucous membrane. The slit-like opening between the vocal cords is the glottis. The trachea, extending below the larynx, is supported by cartilaginous rings, which are open on the dorsal side. The cartilages of the larynx are derived from modified visceral arches.

\section{Appendicular Skeleton}

Typically, vertebrates have two pairs of limbs, pectoral and pelvic, each with its girdle of bones connecting it with the body. As a matter of adaptation these limbs undergo great modification in various forms, and one, or even both pairs, may be entirely absent. From the amphibians to the mammals the limbs of all forms are easily recognized as homologous. But the limbs (fins) of fishes are of an entirely different structure, and although probably homologous, are not easily compared with those of higher vertebrates.

Above the fishes the parts of the pectoral girdle and forelimb may be homologized with the parts of the pelvic girdle and hind limb. Each part of one is represented by a similar part in the other.

\section{Girdles and Limbs of the Shark}

The pectoral girdle is the U-shaped arch of cartilage which supports the pectoral fins. It is made up of right and left halves united by a ligament in the mid-ventral line. The articular (glenoid) surface for articulation of the fin is well up on the side. The part of the girdle dorsal to this is known as the scapular region, the most dorsal part of which forms a distinct cartilage, the suprascapular. The part of the girdle ventral and medial to the glenoid surface is the coracoid region.

The pectoral fin is attached to the pectoral girdle at the glenoid surface. It consists of: (a) three basalia, large cartilages articulating with the glenoid surface; (b) many radialia or fin rays extending beyond the basalia; and (c) actinotrichia, the very numerous horny threads extending beyond the radialia and supporting the greater portion of the fin. 
Attempts have been made to trace homologies between the basalia and radialia of sharks and the bones of the arm and the hand of higher vertebrates.

The pelvic girdle is much simpler than the pectoral and consists merely of a bar of cartilage.

The pelvic fin is also simpler than the pectoral. It consists of: (a) two basalia, (b) many radialia (in males the posterior one is much elongated to form the support for the clasper), and (c) actinotrichia, as in the pectoral fin.

\section{Girdles and Limbs of Necturus}

Study a mounted skeleton. The pectoral girdle is somewhat primitive and consists mainly of cartilage. Extending dorsally from the glenoid surface (the point of articulation of the arm) is a short scapula, the only part of the girdle composed of bone. Attached to the distal end of the scapula is a cartilaginous suprascapula. The large cartilage extending medially from the glenoid surface is the coracoid region; the one extending anteriorly is the procoracoid.

The forelimb is composed of humerus, articulating with the girdle; ulna and radius, the bones of the forearm; carpus (wrist) of several cartilages; metacarpus of four bones; and the phalanges of the digits. The thumb is missing. Compare the specimen with a chart to understand the relationship of the cartilages and bones of wrist and hand. Also, compare Necturus with the chart of the typical vertebrate limb.

The pelvic girdle represents a transition stage between the cartilaginous condition of the elasmobranchs and the bony girdle of reptiles. It consists of a pelvic plate. The socket for articulation of the leg is known as the acetabulum. Medial and anterior to the acetabulum lies the pubic region; posterior to this is the ischial region; attaching the girdle to the vertebral column is the ilium. Ilium and ischium are partly bony.

The hind limb is like the forelimb. It is composed of femur, articulating with the girdle at the acetabulum; tibia and fibula, bones of the shank; tarsus of several cartilages; metatarsus of four bones; and phalanges of the digits. The first toe is missing. 


\section{Pectoral and Pelvic Girdles of the Alligator}

The pectoral girdle consists of a dorsal scapula; a ventral coracoid; and a slender interclavicle bone between the two coracoids. There are no clavicles.

The pelvic girdle is wholly ossified and contains the typical three regions. The ilium extends dorsally and forms an articulation with the vertebral column; the pubis extends ventrally and anterior; the ischium ventrally and posterior. The ischia of the two sides meet and form the ischial symphysis.

\section{Pectoral Girdle and Fore Limb of the Cat}

I. Scapula.-This is the shoulder blade. At the ventral end is the glenoid fossa for reception of the humerus bone of the arm. A short spine, the coracoid process, projects medially from the anterior end of this fossa. This is a remnant of the coracoid bone found in certain lower vertebrates. The prominent keel on the outer surface of the scapula is the spine. This has two projections; the distal one is the acromion, the other the metacromion.

2. Clavicle.-In some mammals, as in man, this is a well developed bar of bone, extending from the scapula to the sternum. In the cat, however, it is greatly reduced, being represented on each side by a short, slender rod of bone entirely embedded in the muscles, and not articulated with any other bones. It is usually absent on mounted skeletons.

3. Humerus.-This is the single bone of the upper arm. At its proximal end is the head, a rounded swelling with a smooth face for articulation with the glenoid fossa. The prominent ridge extending from the lateral border of the head is the greater tuberosity; the less conspicuous ridge on the medial side of the head is the lesser tuberosity. The depression between the two is the bicipital groove. From the ventral end of the greater tuberosity the pectoral ridge extends down the anterior face of the shaft. Not quite halfway down, it is joined on the lateral side by the deltoid ridge, which starts at the posterior end of the greater tuberosity. The distal end of the humerus presents an eminence on either side, the outer and inner condyles. Above the inner condyle the shaft is pierced by the supracondyloid foramen, 
for the passage of a blood vessel and a nerve. Between the two condyles is the smooth surface for articulation of the ulna and radius. Above these on the posterior face is a depression, the olecranon fossa, for reception of the olecranon process of the ulna.

4. Ulna.-This is the longer of the two bones of the forearm. The notch into which the humerus fits is the greater sigmoid cavity. Just distal to this is a smaller transverse concavity, the lesser sigmoid cavity, for articulation with the radius. The portion of the ulna proximal to the greater sigmoid cavity is the olecranon process. The projection at the distal end of the ulna is the styloid process.

5. RAdrus. - This is the shorter of the two bones of the forearm. Proximally, by means of its head, it articulates with the humerus and the ulna. A small projection toward the ulna, slightly distal to the head, is the bicipital tubercle. As in the ulna, the process at the distal end of the radius is the styloid process.

6. Carpus.-The seven bones in the wrist make up the carpus. These are arranged in two rows. The three bones in the proximal row, beginning on the medial side, are: scapholunar, cuneiform, and pisiform. In kittens the scapholunar is represented by three bones; in man by two, the scaphoid and lunar. The four bones of the distal row, beginning medially, are: trapezium, trapezoid, magnum, and unciform.

7. Metacarpus. - This consists of the five long bones of the hand. For convenience they are numbered from $x$ to 5 , beginning on the medial side.

8. Phalanges. - The cat has five digits on the front foot, each of which, with the exception of the thumb, contains three phalanges; the thumb has two phalanges. The distal phalanx of each digit has attached to it a retractile claw.

\section{Pelvic Girdle and Hind Limb of the Cat}

I. Innominate.-The pelvic girdle consists of two innominate bones, one on each side, the two joining in the mid-ventral line to form the pubic symphysis. Each innominate has near the center of its lateral surface a depression, the acetabulum, for the reception of the head of the femur. The acetabulum marks 
the point of union of the three component parts of the innominate. (In kittens the sutures between them still exist, as well as a small acetabular bone in the floor of the depression.) The parts of the innominate are: (a) the ilium, extending anteriorly from the acetabulum and connecting with the sacrum; (b) the ischium, posterior to the acetabulum; and (3) the pubis, the ventral bar of bone adjoining the pubic symphysis.

The large opening between ischium and pubic is the obturator foramen. It will be referred to frequently when the muscles of the hind leg are studied.

2. Femur. - This is the single bone of the thigh. It has a large globular head which fits into the acetabulum. The large roughened projection lateral to the head is the great trochanter which serves for the attachment of many muscles. The lesser trochanter is a small tubercle on the posterior side, a short distance below the head. The large depression on the posterior side between the head and great trochanter is the trochanteric fossa. The prominences on the distal end of the femur are the lateral and medial condyles, and the groove between the condyles is the intercondyloid fossa.

3. Patella. - This is the knee cap. It is a sesamoid bone; that is, it is formed by ossification of part of a tendon. There are other sesamoid bones in the skeleton, but this is the largest.

4. Tibia.-This is the larger of the two bones of the shank and is the longest bone of the body. It articulates with the two condyles of the femur by means of the lateral and medial tuberosities. Anteriorly the tibia has a prominent crest which disappears distally. The projection on the distal end of the tibia is the medial malleolus.

5. Fibula.-The fibula is the slender bone of the shank. It articulates with the tibia at both ends and with the ankle distally. The expanded proximal end is the head; the prominence at the distal end is the lateral malleolus.

6. TARsus.-The tarsus is composed of the seven bones in the ankle. The calcaneus (sometimes calcaneum) is the largest of the ankle bones and forms the heel. The astragalus forms the chief articulation between the foot and the tibia. The navicular or scaphoid is distal to the astragalus and is usually described as boat-shaped. The four bones in the distal row, beginning 
laterally, are: the cuboid, and the lateral-, the intermediate-, and the medial cuneiform.

7. Metatarsus. - This is composed of the five long bones of the foot, the first of which is rudimentary.

8. Phalanges. - The first toe is absent. Each of the four remaining digits has three phalanges. As in the fore limb, the distal phalanx of each digit carries a retractile claw. 


\section{THE MUSCULAR SYSTEM}

Much of the laboratory work for the rest of the course will consist of dissection. Dissection means separating the parts so that they may be more easily seen; very little cutting is required. Blunt instruments and the fingers often make the best dissecting tools for separating structures. Follow directions carefully. Be sure that you know what you are going to do before you do it. In case of doubt, ask the instructor.

\section{Muscles of the Shark}

A detailed comparative study of muscles is very unsatisfactory because of the great variability in arrangement and function, even among closely related species. However, the primitive arrangement of muscles should be clearly understood. In the lowest vertebrates, as in amphioxus, the greater part of the external musculature consists of a series of zigzag bands on each side of the body called myomeres, each separated from the next by a connective tissue septum, the myocomma. Each myomere is composed of many muscle fibers which run from one myocomma to the next.

From the shark remove a narrow strip of skin from the dorsal to the ventral side in the region of the pelvic fin, and observe the primitive arrangement of the muscles. In the vicinity of the lateral line a connective tissue septum divides the myomeres into a dorsal epaxial region and a ventral hypaxial region. The muscles of the two sides of the body never overlap but are separated in the mid-ventral line by a connective tissue partition, the linea alba.

Where paired limbs occur some of the myomeres are modified in character and position to form the musculature of the limbs. Remove the skin from the pelvic girdle and expose a mass of muscle originating from the myomeres of the body and inserting on the fin. By cutting through this muscle mass its origin from the myomeres beneath may be readily seen. In land verte- 
brates, where greater support is needed, almost all myomeres are so modified that the original segmental arrangement of the muscles is no longer recognizable.

\section{Muscles of the Cat}

A cat will be supplied that has been embalmed in such a way that it does not need to be immersed in a preserving fluid. It must be kept in its container, however, with the cover on tight, when not in use. This is important. The cat will remain in good condition throughout the semester if properly cared for.

Skin your own cat. Before proceeding ask the instructor for directions. It is preferable, though not essential, to skin the cat a day or two before using it for muscle dissection to allow the excess embalming fluid to drain off. During the skinning notice that the skin is held to the muscular wall underneath by a loose fibrous tissue, the superficial fascia. Observe also that certain muscles, particularly in the thoracic region, have their insertions in the skin. If your cat is a female, the mammary glands will be noticeable; in some cases milk may be present.

In speaking of the muscular system reference is made to the voluntary muscles only. Each muscle is attached at each end to some other structure, most commonly, though not always, to bone. The less movable end of a muscle is known as the origin; the more movable end, as the insertion. A muscle may have more than one point of origin or insertion. Attachment of a muscle is frequently made by means of a white fibrous cord called a tendon. A broad flat tendon is known as an aponeurosis. Occasionally part of a tendon ossifies, forming a sesamoid bone. (The patella is a good example.)

Surrounding each muscle, and also groups of muscles and the musculature of the body as a whole, are sheets of connective tissue known as fasciae. Dissection of muscles consists almost wholly of tearing and separating these. Fascia frequently serves also as the origin or insertion of a muscle.

Muscles are often described by their actions. In this connection the following terms are important:

Flexor, a muscle which bends a joint.

Extensor, a muscle which straightens a joint. 
Adductor, a muscle which tends to draw a part toward the median line.

Abductor, a muscle which tends to draw a part away from the median line.

Rotator, a muscle which rotates a limb, or part of it, on its long axis.

There are about five hundred voluntary muscles in the cat. While the descriptions given here are limited to the hind leg, dissect as many of the other muscles as you wish. The muscles are described in the order in which they are most conveniently dissected. Careful comparison of the muscles with the descriptions will usually enable you to make certain that you have the right muscle. In case of doubt refer to Reighard and Jennings, "Anatomy of the Cat." Always have a skeleton before you. First find the origin and insertion of the muscle on the skeleton, and then find it on the specimen. Observe the direction in which the muscle fibers run; they are not always parallel to the long axis of the muscle. Trace each muscle to its origin and insertion, but do not remove a muscle at its origin or its insertion unless specifically told to do so. However, a muscle may be cut through the middle to expose underlying muscles. Try not to cut the larger blood vessels; a few will be mentioned as the dissection proceeds.

Demonstrate dissections to the instructor, and be prepared at any time to point out any muscle and give its origin, insertion, and action. A clean-cut dissection will have the fat and connective tissue removed so that the muscles stand out clearly.

\section{Superficial Muscles of the Thigh}

Remove the fat and superficial fascia from one thigh and shank. If the cat is a male, be careful not to injure the spermatic cord which emerges from the body cavity and extends to the testis. Place the cat ventral side up.

I. Sartorius.-There are only two superficial muscles on the median side of the thigh; both are broad and flat. The sartorius covers the cephalic half of the median surface of the thigh; the gracilis, to be studied next, covers the caudal half. Distally these two muscles nearly meet; proximally they diverge leaving between them a shallow depression known as Scarpa's 
triangle (a landmark of importance in human anatomy). The sartorius originates from the ventral border of the ilium, and is inserted on fascia proximal to the patella, on the patella, and on the proximal portion of the tibia.

Action: to adduct and rotate the thigh, and to extend the shank.

2. Gracilis.-This broad flat muscle occupies most of the medial surface of the thigh not covered by the sartorius. It originates by a strong tendon from the caudal three-fourths of the pubic symphysis. Part of this tendon is common to the gracilis muscles of both legs and also gives origin to some fibers of the adductor femoris muscles of both legs. The gracilis inserts by a thin aponeurosis on fascia on the shank and on the medial side of the proximal end of tibia.

Action: to adduct and extend the thigh; to flex the shank.

Extending across Scarpa's triangle are the femoral artery (injected with yellow coloring material), femoral vein (dark), and the femoral nerve (white). If traced toward the foot each will be found to give off many branches to the muscles.

Turn the cat over. If the superficial fascia has been cleanly removed, several muscles will be exposed.

3. Biceps Femoris.-This is a large triangular muscle covering the caudal two-thirds of the lateral surface of the thigh. It is narrow at the proximal end and widens distally. Before dissecting it, read about the next muscle, the tenuissimus, which adheres closely to the underside of the biceps femoris and may be easily destroyed. The biceps femoris originates from a small area on the posterior end of the ischium; insertion is on the lateral margin of the patella and by means of fascia, on the tibia. Separate this muscle from the surrounding tissues, being careful not to injure other muscles or their tendons. Carefully cut it transversely through the middle and expose the tenuissimus muscle and the large sciatic nerve.

Action: to abduct the thigh and flex the shank.

4. Tenuissinus.-This is an extremely slender muscle, beneath and closely adherent to the biceps femoris. It is easily overlooked. It originates from the transverse process of the second caudal vertebra, passes to the caudal border of the biceps femoris, and is inserted by the same fascia on the tibia. 
Action: to aid the biceps femoris.

5. Caudo-femoralis. - This is partly covered by the anterior border of the biceps femoris. It originates from the transverse processes of the second and third caudal vertebrae. The fibers converge, and about half way down the thigh end in a slender tendon, by means of which this muscle is inserted on the lateral border of the patella.

Action: to abduct the thigh; to extend the shank.

6. Gluteus Maximus.-This short muscle originates anterior to the proximal end of the caudo-femoralis from the transverse processes of the last sacral and first caudal vertebrae and from dorsal fasciae. The fibers converge and are inserted just below the great trochanter. The fibers also frequently intermingle with the fibers of the next muscle, the tensor fasciae latae, making it difficult to find the exact boundary of the muscle.

Action: to abduct the thigh.

7. Tensor Fasciae Latae.-Cut the sartorius muscle through the middle. Under this and extending around to the lateral side of the thigh is a heavy, glistening fascia, the fascia lata (lata, wide). Slit it lengthwise on each side, being careful not to injure the quadriceps femoris muscle which lies underneath. Probe under the fascia and trace it to its insertion on the patella. The proximal end of the fascia lata is attached to a triangular muscle, the tensor fasciae latae, which originates partly from the outer ventral border of the ilium, and partly from the fascia covering the next muscle, the gluteus medius.

Action: to stretch the fascia lata (as its name implies) and to extend the shank.

8. Gluteus Medius.-This is the heavy muscle anterior to the gluteus maximus and largely covered by the tensor fasciae latae. It originates from the dorsal half of the lateral surface of the ilium, from dorsal superficial fasciae, and from the tips of the transverse processes of the last sacral and first caudal vertebrae. The fibers converge and join a large central tendon inserted on the great trochanter of the femur.

Action: to abduct the thigh.

\section{Deep Muscles of the Thigh}

To expose the deeper muscles, cut through the middle of the tensor fasciae latae and caudo-femoralis and pin back the proxi- 
mal ends. Cut the insertions of the gluteus maximus and gluteus medius and roll these muscles back out of the way. Much of the origin of the gluteus medius will have to be removed, leaving this muscle attached mainly by a small area of dorsal fascia. There should now be in view a fan-like mass of several small muscles radiating around the great trochanter.

9. Piriformis. - This is a small triangular muscle. It is now the only muscle left in this region that lies over the sciatic nerve. It originates from the transverse processes of the last two sacral and first caudal vertebrae. The fibers converge and are inserted by a flat tendon on the great trochanter. Loosen the insertion of the piriformis and pin the muscle back. Pull the sciatic nerve to one side to expose the underlying muscles.

Action: to abduct the thigh.

Io. Gluteus Minimus.-This is an elongated muscle, originating from almost the whole ventral half of the lateral surface of the ilium. It is inserted by means of a strong tendon on the lateral side of the great trochanter.

Action: to rotate the thigh.

I I. Gemellus Superior.-This is a short, broad, triangular muscle, partly covered by the piriformis, but extending beyond it on each side. It originates from the dorsal border of the posterior half of the ilium and the anterior third of the ischium. The fibers converge rapidly to a tendon that inserts on the great trochanter.

Action: to abduct the thigh.

I2. Obturator Internus.- This muscle lies caudal to the gemellus superior. Its origin is on the inner surface of the ischium near the symphysis. The fibers pass over the dorsal border of the ischium; insertion is by means of a strong tendon in the trochanteric fossa of the femur.

Action: to abduct the thigh.

I3. Gemellus Inferior.-This is a flat muscle almost entirely covered by the obturator internus. Only a small portion shows posterior to the obturator internus. It originates on the lateral surface of the ischium and inserts on the same tendon with the obturator internus. The obturator internus must be cut where it passes over the ischium if much of the gemellus inferior is to be seen.

Action: to abduct the thigh. 
I4. Quadratus Femoris. - This is the most posterior of the fan-like mass of muscles around the great trochanter. It originates from a triangular area on the lateral surface of the ischium, near the posterior end, and inserts on the greater and lesser trochanters of the femur.

Action: to extend and rotate the thigh.

I5. Capsularis. - This is a small muscle entirely covered by the gluteus minimus. It originates on the lateral surface of the ilium near the acetabulum, and inserts on the femur distal to the great trochanter. It may be seen by removing the gluteus minimus at its insertion. It will be seen again when the quadriceps femoris muscle is dissected.

Action: to rotate the thigh.

There now remain several muscles, the semitendinosus, the semimembranosus, the adductor femoris, and the quadriceps femoris, which show on both sides of the thigh, but are more easily dissected from the medial side. Cut transversely through the middle of the gracilis, if this has not already been done.

I6. Semitendinosus.--This is the long muscle forming the caudal border of the thigh. The proximal end is on the lateral side; the distal end is on the medial. It originates on the posterior end of the ischium, and inserts on the proximal end of the tibia by means of a tendon.

Action: to flex the shank.

i7. Semimembranosus.-This is the thick muscle, with fibers loosely held together, lying next to the semitendinosus. It originates from the caudal border of the ischium and inserts on the medial side of distal end of the femur and the proximal end of the tibia.

Action: to extend the thigh.

i 8. Adductor Femoris.- This is a large triangular muscle between the semimembranosus and the femur. The fibers are loosely united, making it difficult to find the boundaries of the muscle. The origin is from the lateral surface of the pubis and ischium, near the symphysis, and from the tendon of the gracilis muscle. The insertion covers almost the whole shaft of the femur.

Action: to extend and adduct the thigh. 
19. Adductor Longus.-This is a small muscle anterior to and slightly overlapping the aductor femoris. It originates with the pectineus from the cranial border of the pubis and inserts by a thin aponeurosis on the femur.

Action: to adduct the thigh.

20. Pectineus.-This is the last and smallest of the muscles on the caudal side of the femur. It is sometimes entirely fused with the adductor longus. It originates from the cranial border of the pubis, and inserts on the femur.

Action: to adduct the thigh.

2I. Iliopsoas.-This is the equivalent of two human muscles, the iliacus and the psoas. It emerges from the body cavity and inserts on the lesser trochanter of the femur. It originates from the centra and transverse processes of ten vertebrae. Do not trace it to its origin; it will be seen again in the study of the internal anatomy.

Action: to rotate flex the thigh.

22. QuAdriceps Femoris.-This is the large mass of muscle covering the whole cranial surface of the femur. It consists of four parts, each of which may be considered a separate muscle, with a common insertion on the patella. The vastus lateralis forms the lateral face of this muscle. It originates on the lateral side of the great trochanter and shaft of the femur. The vastus medialis forms the medial face of the quadriceps femoris, and has its origin from a long area on the median side of the femur. The rectus femoris lies between the vastus lateralis and vastus medialis, and originates from a triangular area just anterior to the acetabulum. It unites with the vastus lateralis about twothirds the way down the femur. Cutting the rectus femoris through the middle will expose part of the vastus intermedius, which lies beneath it. The vastus intermedius originates from nearly the whole length of the femur. It is usually difficult to separate it cleanly from the vastus medialis. At the proximal end of the quadriceps femoris, between the vastus lateralis and rectus femoris, the capsularis muscle may be seen.

Action: to extend the shank.

23. Obturator Externus.-Cut transversely through the middle of the semitendinosus, semimembranosus, and adductor 
femoris so as to swing the leg forward until the toe points towards the head. The large, flat, triangular obturator externus muscle should now be exposed. It originates on the medial border of the obturator foramen and inserts in the trochanteric fossa.

Action: to rotate the thigh.

\section{Muscles of the Shank and of the Foot}

Skin the foot and remove all superficial fascia from both shank and foot. This will involve removal of the insertions of some of the thigh muscles. From now on it is important, at the end of each laboratory period, to wrap the shank and foot with cheese cloth soaked in embalming fluid, to prevent the muscles from becoming dry.

Most of the muscles of the shank extend onto the foot; their tendons should be traced to the points of insertion.

24. Gastrocnemius.-Almost all of the mass of muscle forming the calf of the leg is the gastrocnemius, composed of two heads, a caput mediale (medial head) and a caput laterale (lateral head). Between the caput mediale and caput laterale lies another muscle, the plantaris. With the handle of a scalpel separate the muscles, beginning in the depression behind the knee. The caput mediale will separate easily; the caput laterale will be difficult to separate from the plantaris. The two heads of the gastrocnemius unite about one-third the way down the shank. The caput laterale originates from four places: from superficial fascia of the shank, from the lateral edge of the patella, from a sesamoid bone on the lateral side of the head of the tibia, and from an aponeurosis covering the plantaris. The caput mediale originates from the distal end of the femur and from a sesamoid bone on the medial side of the head of the tibia. The tendons of the two heads of the gastrocnemius and of another muscle, the soleus, unite to form the large tendon of Achilles, which inserts on the calcaneus bone.

Action: to extend the foot.

25. Plantaris.-Dissection of the gastrocnemius has already revealed this muscle. It originates by a tendon (which it shares with the caput laterale) from the lateral edge of the patella, and from the sesamoid bone on the lateral side of the head of the tibia. The tendon of the plantaris forms the core of the tendon 
of Achilles, which should be carefully split open to demonstrate this fact. The tendon of the plantaris passes through a groove and inserts on the ventral side of the calcaneus.

Action: to extend the foot.

26. Soleus.-This is the remaining muscle of the calf of the leg with an insertion on the tendon of Achilles. It lies on the lateral side and originates from the proximal half of the fibula.

Action: to extend the foot.

27. Flexor Digitorum Brevis.-This is a flat muscle on the sole of the foot. It originates from the tendon of the plantaris, a fact revealed by removal of the plantaris tendon at its insertion on the calcaneus. Distally the flexor digitorum brevis divides into four tendons, one going to each toe.

Action: to flex the toes.

28. Quadratus Plantae.-Cut through the middle of the flexor digitorum brevis and expose the wide tendon beneath. This is the combined tendon of the flexor digitorum longus and the flexor hallucis longus. On it is inserted the small triangular quadratus plantae muscle, which originates from the lateral surface of the calcaneus and cuboid.

Action: to hold the tendon in place.

29. Flexor Digitorum Longus.-Beginning on the sole of the foot trace back the smaller and more medial branch of the combined tendons of the flexor digitorum longus and the flexor hallucis longus until this muscle is reached. The flexor digitorium longus originates from the surface of the tibia and the head of the fibula. Distally the tendon, after the flexor hallucis longus has united with it, divides into four branches, one for each toe.

Action: to flex the toes and extend the foot.

30. Flexor Hallucis Longus. - This muscle lies lateral to the flexor digitorum longus and greatly exceeds it in size. It originates from the shaft of the tibia, and from the head and shaft of the fibula. In five-toed mammals the tendon of the flexor hallucis longus inserts on the big toe (hallux); in the cat it unites with the tendon of the flexor digitorum longus.

Action: with the flexor digitorum longus to flex the toes and extend the foot. 
31. Popliteus.-The short triangular muscle behind the knee, near the proximal end of the flexor digitorum longus, is the popliteus. It originates by a strong tendon from the lateral side of the femur; its fibers diverge obliquely and are inserted on the medial side of the proximal end of the tibia.

Action: to rotate the shank.

32. Tibialis Posterior.-This is a slender muscle completely covered by the flexor digitorum longus. It originates from the head of the fibula and from the tibia near its head. About half way down the tibia it passes into a tendon, which passes through a groove on the distal end of the tibia and inserts on the scaphoid and medial cuneiform bones.

Action: to extend the foot.

33. Extensor Digitorum Longus.-On the dorsal side of the foot is a tendon with four branches going to the toes. Trace this tendon back through a small ligament on the foot to a muscle which passes under the large transverse ligament just above the ankle. This is the extensor digitorum longus which should be separated from the large muscle lying between it and the tibia. The extensor digitorum longus originates by a tendon from the lateral side of the distal end of the femur. Insertion is on the upper surface of each digit.

Action: to extend the toes and flex the foot.

34. Tibialis Anterior.-This is the long muscle between the extensor digitorum longus and the tibia, already partly dissected. It originates from the proximal portions of both tibia and fibula and inserts by a tendon on the first metatarsal. The tendon, together with the extensor digitorum longus muscle, is held down by the transverse ligament.

Action: to flex the foot.

35. Peroneus Longus. - There now remain three peroneus muscles on the lateral side of the shank, between the extensor digitorum longus and the flexor hallucis longus. The peroneus longus is the outermost of these muscles. It originates from the proximal half of the fibula; and soon passes into a tendon, which continues through a groove on the distal end of the fibula and inserts on the proximal parts of all the metatarsals.

Action: to flex the foot. 
36. Peroneus Tertius.-Beneath the peronous longus lies the slender peroneus tertius muscle, whose tendon passes with that of the peroneus brevis through the groove on the fibula, and then to its insertion on the lateral side of the fifth toe. It originates on the fibula.

Action: to abduct and extend the fifth toe.

37. Peroneus Brevis.-This is the third muscle of the peroneus group. It originates from the distal two-thirds of the fibula, which it almost surrounds and its tendon, after passing over the end of the fibula, inserts on the lateral side of the fifth metatarsal.

Action: to extend the foot.

There are many small muscles on the foot which have not been mentioned. No attempt will be made to dissect them. 


\section{THE DIGESTIVE AND RESPIRATORY SYSTEMS}

The digestive and respiratory systems are so closely associated, particularly in lower vertebrates, that it is convenient to study them together. The digestive system includes all organs involved in the taking in and digestion of food, and in the disposal of the undigested wastes. In vertebrates this system is composed of the alimentary canal, a continuous tube extending from mouth to anus, and a number of digestive glands opening into it. The organs concerned with obtaining oxygen and giving off carbon dioxide constitute the respiratory system. While dissecting the digestive and respiratory systems attention will be called occasionally to other structures most conveniently studied at this time.

\section{Comparative Anatomy of Teeth}

As the teeth of nearly all vertebrates are derived from placoid scales, they are similar in general structure. They differ greatly, however, in shape, number, manner of attachment, and method of succession in various animals. A few representative species will be studied.

LAMPREY.-The tooth-like structures form a circle around the mouth. They are not real teeth, but are simply projections of the horny layer of the skin.

Shark.-Examine the prepared jaw of a large shark. The teeth have no roots, but are attached to the tissues. They are all alike (homodont) except in size. Each functional tooth has behind it a series of developing reserve teeth. If a functional tooth is lost, it is immediately replaced by a reserve tooth behind it. This replacement may take place an unlimited number of times, a condition known as polyphyodont.

A Bony Fish.- The dentition here is also homodont and polyphyodont. The teeth are without roots, but are firmly attached to the surface of the bone (acrodont). In many fishes 
they occur not only on the jaws, but may sometimes be found on the vomer, palatine, pterygoid, and parasphenoid bones.

Giant Salamander.-Compare with the fish. The teeth are pleurodont, that is, attached to the inner surface of the jaw. A similar condition exists in frogs, but our common toads have no teeth.

TURTLE.-Adult turtles never possess teeth although rudiments may exist in the embryo. The jaws are covered instead by a thick hard horny layer, usually with a very sharp edge.

Alligator.- The teeth have roots embedded in sockets in the jaw (thecodont). This is unusual in reptiles, but is the common condition in mammals.

Bird.-Compare with the turtle. No living birds have teeth, but some fossil forms were abundantly supplied with them.

CAT.-The teeth are thecodont (set in sockets), heterodont (of various shapes), and diphyodont ("milk" teeth precede the permarient set). These conditions are typical of mammals. The different kinds of teeth found in the cat have already been studied; review them again if necessary.

RoDENT.-The long curved incisors, suited for gnawing, bear hard enamel on the anterior face only. These teeth grow throughout the life of the animal.

Dental Formula.-The number and character of the teeth are constant for members of the same species, but vary greatly in different species. To express in a brief form the dental condition, a dental formula is used. The formula for the cat is

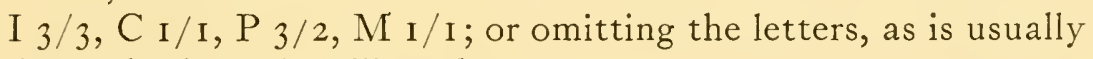
done, the formula will read

$$
\frac{3, \mathrm{I}, 3, \mathrm{I}}{3, \mathrm{I}, 2, \mathrm{I}}
$$

\section{Digestive and Respiratory Organs of the Shark}

If your shark is a female ask for instructions before opening the body cavity; if you have a male open the body cavity by making a longitudinal incision on each side from the pelvic region to the pectoral, and then making transverse cuts at each end so as to remove the ventral body wall. Most of the viscera 
will now be in view. Begin at the corner of the mouth and cut back through the gill arches on the left side until the body cavity is reached. Find the following:

I. Pharynx, the region in the back part of the mouth cavity common to both digestive and respiratory systems. Lay back the floor of the mouth and study the gills and the gill arches. The gills exist as rows of delicate gill filaments radiating from the membrane covering the gill arches. The first arch, situated on the anterior wall of the first gill slit, is the hyoid arch. It is termed a hemibranch as it bears gill filaments on the posterior side only. A holobranch has gill filaments on both sides of the arch. How many holobranchs and hemibranchs are there and to which arches do they belong? The hyoid arch, in addition to bearing gill filaments, supports the tongue. The small cartilaginous processes on the inner borders of the gill arches are the gill rakers.

The spiracles, bearing gill filaments and opening into the pharynx, have already been studied.

2. Oesophagus, an exceedingly short tube connecting the pharynx with the stomach.

3. Stomach, the large J-shaped organ extending more than half the length of the body cavity. It may be partly covered by the liver. The size of the stomach will depend to a large extent on the amount of food it contains. It is commonly constricted near the middle. Slit open the stomach, wash out anything it may contain, and examine the inner surface. The anterior part contains finger-like papillae; further back are longitudinal folds, which vary in size with the degree of contraction of the stomach. In a stomach distended with food the longitudinal folds may wholly disappear. A pyloric valve is present on the caudal end of the stomach.

4. Intestine, extending from stomach to anus, and consisting of three regions. The first part, the duodenum, is short; it lies between the stomach and the second region, the large spiral valve. The spiral valve constricts posteriorly to form the short third division of the intestine, the rectum, which opens into the cloaca. Attached to and opening into the rectum is a finger-like projection, the rectal gland, the function of which is not known. 
Slit open the spiral valve and observe the large spiral fold which serves to retard the passage of food, and thus secures more complete digestion and absorption.

5. Liver, large and oily, and consisting of several lobes united at the anterior end. The gall bladder, usually recognizable by its greenish color, lies embedded in the right side of the smallest lobe of the liver. Trace the bile duct. It enters the intestine at the point where the duodenum joins the spiral valve.

6. Pancreas, a pale bilobed mass, one part of which lies on the duodenum and the other, a more elongated portion, lies between the stomach and spiral valve. The pancreatic duct may be difficult to find. It is a short, white duct on the dorsal side of the more compact lobe of the pancreas, sometimes embedded in the tissue, and enters the anterior end of the spiral valve.

7. Spleen, the dark colored, triangular organ attached to the stomach. This structure is associated with the organs of circulation.

Before replacing the shark in its container remove the major portion of the liver, leaving the base of the liver and the gall bladder and bile duct intact. Removal of the liver will aid in preventing the specimens from becoming oily.

\section{Digestive and Respiratory Organs of Necturus}

Open the body cavity by making a longitudinal incision from one side of the anus through the pelvic girdle to the pectoral girdle. Spread apart the two flaps; cut them off if necessary. Identify the following organs: liver, gall bladder and bile duct, stomach, pyloric valve, small intestine, large intestine, cloaca, pancreas and spleen. Also, locate the lungs. These are a pair of elongated, thin, semi-transparent structures lying dorsal to the liver and stomach.

Cut through the lower jaw and gill arches on each side and expose the mouth cavity and pharynx. Find the posterior nares, the internal openings of the nasal passages. These are located at the posterior ends of the rows of teeth and are covered with small flaps of skin that act as valves. The tongue is supported by the hyoid arch. The walls of the pharynx are pierced by two pairs of gill slits. The walls of the gill slits, unlike those of the 
shark, bear no gill filaments; the gills are external in position. Find the opening into the oesophagus. On the floor of the pharynx just anterior to the opening to the oesophagus is a tiny slit, the glottis, which leads to a small, very primitive larynx. The glottis is supported by two very small arytenoid cartilages, probably derived from the seventh visceral arch. The larynx is joined to the lungs by a short trachea. Slit open a lung and observe that the interior surface is smooth. This is a primitive condition.

Necturus has three methods of obtaining oxygen: through the gills, through the skin, and through the lungs. When using the lungs air passes through anterior nares, nasal passages, posterior nares, mouth cavity, pharynx, glottis, larynx, trachea and lungs.

\section{Digestive and Respiratory Organs of the Cat}

Remove the skin and superficial fascia from the head and neck. On either side of the neck lies the large external jugular vein. Trace it toward the head. At about the angle of the jaw it will be seen that the external jugular is formed by the confluence of two large veins: the posterior facial bringing blood from muscles and glands in the region of the ear, and the anterior facial returning blood from the face and tongue. A communicating branch connects the anterior facials of the two sides. A pair of lymph glands lie along the anterior facial near its union with the posterior facial. These may be removed.

Salivary Glands.-Remove the skin and superficial fascia from the head and neck. There are three important salivary glands which empty their secretions into the mouth cavity. The parotid gland, the largest of the salivary glands, is a large lobulated mass at the base of the ear. Trace its white duct (Stensen's duct) across the surface of the large masseter muscle to the corner of the mouth, where it opens near the last premolar tooth. The submaxillary and sublingual glands lie under the posterior angle of the jaw, somewhat deeply embedded. Do not mistake the two lymph glands on the surface for them. The duct (Wharton's duct) of the submaxillary gland extends along the under side of the mandible and opens on the floor of the mouth just back of the incisor tecth through a small papilla. 
The sublingual, a small gland, lies close to the submaxillary and along its duct. The duct of the sublingual parallels that of the submaxillary and opens with it.

Thyroid Glands.-Expose the proximal end of the trachea by removing the superficial muscles of the front of the neck. The thyroid glands will appear as dark colored bodies on either side of the trachea. The thyroids are endocrine glands and have nothing to do with digestive or respiratory systems.

On each side of the trachea and extending parallel to it are the vagus (tenth cranial) nerve, the common carotid artery carrying blood to the head, and the internal jugular vein returning blood from the brain. Behind the trachea lies the oesophagus.

With bone forceps cut through the mandible on each side behind the corners of the mouth. Continue the cut along one side of the neck until the first rib is reached. Lay back the jaw so as to expose the structures of the mouth and pharynx.

Tongue.-It is a muscular organ attached at its posterior end. The dorsal surface contains papillae of four kinds: (a) filiform, numerous, simple, and sharp pointed; (b) fungiform, enlarged at the tips and scattered over the middle of the tongue; (c) flat, numerous on the sides of the base of the tongue; (d) circumvallate, blunt and surrounded by a trench. These last are not numerous; when distinct they are arranged in a $V$ near the base of the tongue.

Pharynx.-The curtain-like structure on the roof of the mouth is the soft palate. Embedded in pockets at the ventral end of the soft palate on each side are the tonsils. Dorsal to the soft palate and communicating with the nasal cavities by means of the choanae, is the nasopharynx. Cut along the roof of the mouth and pull aside the soft palate; find the openings of the Eustachian tubes in the dorsal wall of the nasopharynx.

Larynx and Trachea.-These constitute the "wind pipe." The walls of the trachea are supported by cartilaginous rings that are incomplete on the dorsal side. The larynx is the enlarged upper end of the wind pipe. Its skeletal parts consist of several cartilages, the largest of which is the thyroid cartilage (Adam's apple of man). The slit-like opening of the larynx is the glottis which is protected from food particles by a cartilaginous flap, the epiglottis, immediately in front of it. 
Cut along the mid-dorsal line of the larynx and continue the cut posteriorly for a few inches along the dorsal side of the trachea. Two folds of skin, one on each side, extend from the base of the epiglottis. These are the false vocal cords. The space in front of them is called the vestibule. A short distance behind them is a second pair of folds, the true vocal cords.

Survey of the Viscera.-Beginning just anterior to the pelvic girdle, cut the abdominal wall on each side, being careful not to injure the internal organs. Continue this cut forward to the first rib, carefully loosening the body wall from the diaphragm when this is reached. Cut the ribs with bone forceps. To expose the contents of the body cavity it will be necessary to remove this flap. In doing so observe the internal mammary arteries and veins that extend onto the chest wall. Without disturbing anything locate: the lungs, enclosing the heart between them; the muscular diaphragm separating thorax and abdomen; the liver, commonly with a portion of gall bladder exposed on its right lobe; the fatty membrane, known as the great omentum, covering most of the abdominal viscera; the stomach, sometimes partly exposed to the left of the liver; the dark colored spleen at the left of the stomach; the many coils of the intestine; and the bladder, just anterior to the pubic symphysis. In cats in an advanced stage of pregnancy the two horns of the uterus will also be prominently in view, often greatly displacing the other internal organs. The membrane lining the body cavity is the peritoneum. A similar one, the pleura, lines the chest cavity.

Observe that the organs are held together and to the body wall by membranes. The membranes attaching the viscera to the body wall are known as mesenteries; those connecting organs with other organs are omenta (singular, omentum).

Oesophagus.- This part of the alimentary canal is a straight tube passing from the pharynx through the diaphragm to the stomach. To see it, pull the left lung toward the right side, but do not cut more tissues than is necessary. The oesophagus is collapsed except when it contains food.

Stomach.-The size of the stomach depends to a large extent on the amount of food it contains; it also varies greatly in different individuals. The cardiac end of the stomach is the region 
where the oesophagus enters; the pyloric end is the part where the small intestine begins. The lateral side of the stomach is known as the greater curvature; the inner side is the lesser curvature. The entrance to the small intestine is guarded by a ring-like thickening, the pyloric valve (pyle, gate).

Small Intestine. - The small intestine is divided into three regions. The first part, the duodenum, begins at the pyloric valve, runs posteriorly on the right side and then forward again on the left side. The place where it turns posteriorly on the left side is arbitrarily chosen as the end, although there is no distinct line of division. The jejunum (meaning empty) is the much convoluted part of the intestine following the duodenum and extending for approximately twenty-five centimeters. Its limits rannot be exactly defined. Its name refers to the fact that in human cadavers it is usually found empty. The remaining part of the small intestine, the ileum (eilein, to roll up), constitutes about two-thirds of the whole. Observe the mesenteries supporting it. The ileo-colic valve lies at the point where the ileum joins the large intestine.

LARge Intestine. - The large intestine is composed of two parts, the colon and the rectum. The colon is the enlarged portion of the intestine into which the ileum enters. Near the point of entrance of the ileum is a blind pouch, the caecum. The colon passes anteriorly, then to the left, and then posteriorly again, forming roughly the ascending, transverse, and descending colon. The rectum is assumed to begin where the descending colon reaches the middle line and extends to the anus, which is surrounded and kept closed by the sphincter ani muscles. Near the anus are two small anal glands. Do not dissect the last part of the rectum until the urogenital system has been studied.

Spleen.-This is the dark red body lying along the greater curvature of the stomach. It is a ductless gland associated with the circulatory system and is not an organ of digestion.

Liver.-This is the largest gland of the body. It is divided into several lobes. The gall bladder lies partially embedded in the liver. Cut away the free ends of the liver and dissect the bile ducts. This requires care, patience, and technique, as the ducts are covered with connective tissue which must be removed. On the duodenum, about an inch from the pyloric valve, is a 
small swelling, the ampulla of Vater, into which the pancreatic duct and the common bile duct empty. The common bile duct (ductus choledochus) is formed by the union of three bile ducts: two hepatic ducts, one from each side of the liver, and the cystic duct from the gall bladder.

Pancreas. - This is a flattened irregular gland, consisting of two lobes, one lying along the duodenum and the other in the great omentum near the greater curvature of the stomach. Do not confuse it with the large lymph glands which lie in the mesenteries. The main pancreatic duct (duct of Wirsung) is short and wide and opens, with the common bile duct, into the ampulla of Vater in the duodenum. The pancreatic duct is formed by two branches, one from each lobe of the pancreas. To find the pancreatic ducts, begin near the ampulla of Vater and scrape off the surface tissue of the pancreas until a white duct appears, then trace this both ways.

Slit open the duodenum and find the opening of the ampulla of Vater on the inside.

Lungs. - Trace the trachea back into the chest cavity and find where it divides into two bronchi, one going into each lung. Work around the blood vessels so as not to injure them. The lungs are paired, many lobed organs. The right and left lungs are completely separated, each lying in its own half of the thorax, with a double septum, the mediastinum, between them. The right lung is slightly larger and is divided into three smaller proximal lobes and a large distal one. The left lung is divided into three main lobes. Trace one of the bronchi as far as possible into its lung. Within the lung it will be found to break up into many branches, the bronchioles. Are the bronchioles supported by cartilaginous rings?

Thymus Gland.-This lies just anterior to the heart on the ventral side of the trachea. Superficially it may resemble fatty tissue. In adult cats it is usually degenerate, but may be easily seen. The thymus is not part of the respiratory system.

Diaphragm.-This muscular partition between thorax and abdomen is to be considered as an organ of respiration. It is an arched muscular structure with the muscle fibers originating from the body wall, vertebrae, and ribs and converging on a central tendon in the middle of the diaphragm for their insertion. 


\section{THE CIRCULATORY SYSTEM}

The circulatory system is in reality made up of two systems, the blood system and the lymphatic system. The blood system is the one usually referred to in speaking of the circulatory system, and includes the heart, blood, and blood vessels. The heart acts as a muscular pump and forces blood through the vessels to all parts of the body. The vessels carrying blood away from the heart are called arteries, and those that bring the blood to the heart are known as veins. The character of the blood carried thus has nothing to do with the naming of the vessels. Arteries and veins are connected by capillaries, thin-walled and microscopic, through which interchange between the blood and the tissues takes place.

The lymphatic system consists of lymph vessels, sinuses, and glands and conveys a colorless fluid, lymph, which bathes the tissues of the body. Some of the lymph glands have already been found. The lymph vessels are very delicate and no attempt will be made to dissect them.

\section{Circulatory System of the Shark}

The arrangement of blood vessels in the elasmobranchs is rather primitive and in many respects is similar to embryonic stages in the development of the mammalian circulation. Hence, a comparison of the shark circulatory system with that of the cat should present an interesting study.

External Axatomy of the Heart.-Make a median incision on the ventral side through the pectoral girdle and carefully continue the incision forward to the mouth. The pericardial cavity, bounded posteriorly by the transverse septum will be exposed. Clean away the tissues ventral to this cavity and expose the heart. The ventricle is the most conspicuous portion of the heart from a ventral view. Its walls are heavily muscular and it contains a single cavity. The short, thick-walled vessel leaving the ventricle is the conus arteriosus. This continues 
forward as the ventral aorta, which gives off afferent branchial arteries to the gills. These will be traced later.

The auricle is a thin-walled sac dorsal to the ventricle. It contains a single cavity that leads to the ventricle. Lift up the ventricle and find the sinus venosus that lies just anterior to the transverse septum. It brings blood from the veins and empties into the auricle.

VEINs.-In the preparation of the specimen the arteries were injected with a colored substance to make them stand out more clearly. The veins, however, have not been so treated and will appear dark with clotted blood, or in some cases may be colorless.

The veins are best dissected by beginning at the sinus venosus and tracing them backward. They are thin-walled and in places dilate to form sinuses. Make a transverse incision across the ventral wall of the sinus venosus. Wash out any clotted blood. Spread the walls apart and look for the openings of vessels into the sinus. In the posterior region near the median line find the apertures of the hepatic sinuses. Stick probes into them and follow the probes back into the liver and expose these large liver sinuses.

Entering the sinus venosus from the lateral sides are the large ducts of Cuvier. These continue partially around the oesophagus and end in the anterior and posterior cardinal sinuses, which extend respectively toward the head and toward the tail. The posterior cardinal sinuses are a pair of very large vessels lying side by side along the dorsal wall of the body cavity. Posteriorly they narrow down and extend between the kidneys. Numerous renal veins may be seen entering the posterior cardinals. Each anterior cardinal sinus extends dorsal to the gill arches in the direction of the eye, where it connects with a large orbital sinus. The anterior cardinal sinus is best dissected by making an incision dorsal to the gills and when the sinus is located tracing it each way.

Entering each posterior cardinal sinus is a subclavian vein which brings blood from the pectoral fin, and a lateral vein which extends along the lateral side of the abdominal cavity from pelvic to pectoral regions. (The lateral veins may have been removed in opening the shark.) The two lateral veins are connected in 
the pelvic region, where they are joined by the iliac veins from the fins.

The hepatic portal system is made up of all the vessels that carry blood from the digestive organs to the liver. The hepatic portal vein is formed by the confluence of the veins from the rectal gland, spiral valve, stomach, spleen, and pancreas, and enters the liver dorsal to the median lobe. Within the liver it forms capillaries. The blood leaves the liver by means of the hepatic sinuses.

The caudal vein enters the body cavity and divides into two renal portal veins, each of which passes to the dorsal side of a kidney where it gives off small branches into the kidney. Blood leaves the kidneys through the renal veins that enter the posterior cardinal veins.

ArTeries.-Dissect the afferent branchial arteries that extend from the ventral aorta to the gills. How many are there? Remove the mucous membrane from the roof of the mouth and trace the efferent branchial arteries which receive blood from the gills. Follow them back into the gills as far as possible and observe that they form a series of loops around the margin of the gills. Short horizontal vessels connect the loops with one another. From the first loop arises the common carotid artery. It divides into external and internal carotids. The internal carotids from the two sides join to form a single vessel, which enters the skull to supply the brain. A coronary artery, arising from one of the efferent branchial vessels, supplies the muscles of the heart and the conus arteriosus with blood.

Follow the efferent arteries inward and posteriorly to where they unite to form the dorsal aorta. This large vessel extends nearly the length of the body. Within the body cavity several vessels arise from the aorta. Sub-clavian arteries extend to the pectoral fins. A coeliac artery, originating just posterior to the transverse septum, supplies stomach, liver, intestine, and pancreas. Small renal arteries go to the kidneys. An anterior mesenteric to the intestines and a gastro-splenic to the stomach, pancreas, and spleen arise close together at about the level of the middle of the spiral valve. Further back a posterior mesenteric goes to the rectal gland. Iliac arteries go to the pelvic fins. Parietal arteries arise along the whole length of the aorta. The 
aorta continues through the haemal arches of the tail vertebrae as the caudal artery.

Internal Anatomy of the Heart.-Make a longitudinal incision through the conus arteriosus and ventricle. Make another incision through the auricle. It should now be possible to look into the heart and see the valves within. The sinuauricular valve appears as two membranous folds bordering the opening between sinus venosus and auricles. The auricularventricular valve consists of flaps guarding the entrance from ventricle to auricle and prevents the backflow of blood into the auricle when the ventricle contracts. Within the conus arteriosus are pocket-like semi-lunar valves that prevent blood from flowing back into the ventricle.

\section{Heart of an Amphibian}

If you are not already familiar with the anatomy of a frog heart, dissect one or study charts showing the structure of an amphibian heart. Observe that there are two auricles and one ventricle, whereas the shark has but one auricle and one ventricle. The left auricle is concerned with the pulmonary circulation and contains pure or oxygenated blood that has come from the organs of respiration. The right auricle, on the other hand, carries impure or reduced blood that has returned to the heart from the tissues, and thus is concerned with the systemic circulation. Blood from the systemic veins passes through the sinus venosus before entering the right auricle.

\section{CIRCULATORY SYSTEM OF THE CAT}

\section{External Anatomy of the Cat Heart}

The heart, in both its embryonic development and in its evolutionary history, begins as a straight tube. Later it becomes folded upon itself forming first two chambers, then three, and finally four divisions, reaching its greatest development in the birds and mammals.

The heart is enclosed in a membranous sac, the pericardium. This should be cut away, but do not remove the heart until after all blood vessels have been studied. 
Ventricles.-The two ventricles constitute the greater visible portion of the heart. The left is much firmer than the right, due to its greater muscular development, by which difference the boundaries between the two ventricles may be fairly well traced. The apex or free tip of the heart lies wholly within the boundaries of the left ventricle.

AUricless.-The auricles are thin-walled sacs anterior to the ventricles. Externally the division between right and left auricles is only slightly indicated. A large part of each auricie is taken up by a flap, the auricular appendage.

Venae Cavae.-Two large veins enter the right auricle. The posterior or inferior vena cava brings blood to the heart from the posterior part of the body; the anterior or superior vena cava brings blood from the shoulders and head.

AortA.-This is the large artery emerging from the left ventricle. It passes between the auricular appendages and soon after leaving the heart bends to the left and passes down the back as the dorsal aorta. It is the beginning of the arterial system.

Pulmonary Vessels. - The pulmonary artery leaves the right ventricle to the left of the aorta and carries blood to the lungs. There are several short pulmonary veins entering the left auricle that bring blood from the lungs back to the heart.

Coronary Vessels.-These are the vessels that take blood to and from the tissues of the heart itself. The left coronary artery extends along the division line between the ventricles on the ventral side, the right coronary artery between the ventricles on the dorsal side. Trace these arteries to their points of origin. The left and the right coronary veins parallel the coronary arteries. The coronary sinus is a vein partially encircling the heart between the auricles and ventricles on the dorsal side. It may be covered with fat. It receives the blood from both right and left coronary veins and empties into the right auricle.

\section{Veins of the Cat}

Considerable variation occurs among blood vessels, particularly as to their points of origin. A blood vessel is therefore 
best identified by the course it takes. In dissecting the veins care must be used not to destroy the arteries, which in general follow more or less the same course. Only the more important arteries and veins are mentioned in this outline; if a more complete description is desired consult Reigard and Jennings.

I. Superior Vena Cava.-This large vein was mentioned previously in the study of the heart. It returns blood from the head, fore limbs, and cranial part of the body to the right auricle. Just before entering the heart it is joined by the azygos vein.

2. Azygos Vein.-This vessel, if traced backward from its point of union with the superior vena cava, will be seen to pass to the right and then backward into the abdomen, where it originates from several small veins from the dorsal muscles. The azygos receives a series of intercostal veins from the muscles of the ribs.

3. Internal Mammary Veins.-A pair of these carrying blood from the ventral body wall and diaphragm run forward on the inner surface of the sternum, unite, and enter the superior vena cava on a level with the third rib.

4. Innominate Veins.-These are the large veins that unite, about on a level with the first rib, to form the superior vena cava. Follow the left one.

5. Vertebral Vein.-This appears to be a short vein entering the innominate on the dorsal side. Bringing blood from the brain it passes through the foramina transversaria of the first six cervical vertebrae before leaving the spinal column to join the innominate. Do not try to trace it within the vertebral column.

6. Subclavian Vein.-This vein comes from the arm and enters the innominate anterior to the first rib. Outside of the thoracic cavity it is known as the axillary vein. Trace it to the elbow.

7. External Jugular Vein.-This unites with the subclavian to form the innominate. It comes from the region of the head. Several veins enter it.

8. Internal Jugular Vein.-This vein enters the cxternal jugular just anterior to the point of union of external jugular and subclavian. It arises from the occipital region and passes posteriorly along the side of the trachea in company with the 
common carotid artery and the vagus nerve. A large lymph vessel, the thoracic duct, enters the external jugular near the place of union with the internal jugular. This is sometimes mistaken for a blood vessel.

9. Transverse Scapula Vein.-This vein returns blood from the arm and shoulder region. It joins the external jugular on the lateral side.

io. Anterior Facial and Posterior Facial Veins.-The external jugular is formed by the union of these two vessels. The posterior facial brings blood from the dorsal side of the head, ear, masseter muscle, parotid gland, and adjacent regions. The anterior facial collects blood from the face, tongue, jaws, and nasal region. A transverse vein connects the anterior facials of the two sides.

Turn now to the veins of the posterior part of the body. Before dissecting them certain of the urogenital organs should be located. If you have not already done so identify the kidneys, large bean-shaped organs on the dorsal wall; adrenal glands, small structures just anterior to the kidneys; urinary bladder in the lower part of the abdomen; ureters, ducts from the kidneys to the bladder; uterus, a branched structure of variable size in the female; spermatic cord and vas deferens of the male. The vas deferens loops over the ureter near where the latter joins the bladder.

i I. Femoral Vein.- - In company with the femoral artery and the saphenous nerve this vein extends across Scarpa's triangle on the inner side of the thigh. The femoral vein, after receiving several smaller veins, enters the body cavity and then becomes known as the external iliac vein. Trace the femoral backward down the leg, dissecting out the larger branches.

I2. Hypogastric (internal iliac) Vein.-Bringing blood from various pelvic organs the hypogastric unites with the external iliac just inside the body cavity. Tracing it backward it extends medially and dorsally.

I3. Common Iliac Vein.-This is formed by the union of the hypogastric and external iliac veins. The two common iliac veins unite in the median line.

I4. Inferior Vena Cava.-Formed by the union of the two common iliac veins, it passes directly forward, through the liver, 
and enters the right auricle. A number of veins enter the inferior vena cava along its course.

I5. Lumbar Veins.-These are several small veins which carry blood from the dorsal musculature to the vena cava. The most cranial of the lumbar veins lies anterior to the diaphragm.

i6. Illo-lumbar Veins.-These are the pair of veins entering the vena cava just anterior to the union of the common iliac veins. They come from the surface of the neighboring muscles.

17. Internal Spermatic Vein (internal ovarian in females). The right spermatic (ovarian) enters the inferior vena cava about the level of the caudal end of the kidney. The left spermatic (ovarian) usually enters the left renal vein. In males the spermatic originates in the testis and passes through the spermatic cord along with the vas deferens. In females, the ovarian originates in the ovary and cranial end of the uterus and passes medially to the vena cava or renal vein.

I8. Renal Vein.-Each originates in the kidney as two branches which fuse together, sometimes before leaving the kidney, sometimes immediately after. The renals enter the vena cava as large veins.

19. Adreno-lumbar Veins.-These veins pass over the surface of the muscles in the neighborhood of the kidney and return blood from the adrenal glands and enter the vena cava at about the level of the cranial end of the kidney.

20. Hepatic Veins.- These are a variable number of short veins carrying blood from the liver to the vena cava. They enter the vena cava just caudal to the diaphragm. To see them cut into the substance of the liver.

21. Portal System.-The portal vein, the main vein of this system, breaks up into capillaries within the substance of the liver. It is formed by the union of several veins leading from the stomach and intestines. The largest of these are:

a. The superior mesenteric, originating from many branches and bringing blood from the small and large intestines.

b. The inferior mesenteric, coming directly from the large intestine.

c. The gastro-splenic, formed by several branches carrying blood from the stomach and spleen. It unites near the pyloric 
end of the stomach with the superior mesenteric to help form the portal. Near this union the portal also receives several other veins from the stomach, duodenum, pancreas, and great omentum.

22. The Pulmonary Verns.-These were mentioned previously. They arise in the lungs and enter the left auricle.

\section{Arteries of the Cat}

I. Pulmonary Artery.-This was observed in the study of the heart. Soon after leaving the right ventricle it divides into two branches, one going to each lung.

2. AORTA.-The origin of this vessel from the left ventricle has already been seen. It curves dorsally and to the left, forming the aortic arch. It then passes caudal on the left side of the vertebral column, pierces the diaphragm, and extends almost the entire length of the abdomen, running more or less parallel to the inferior vena cava. According to the region it is designated thoracic or abdominal aorta. Soon after leaving the heart the aorta divides into two main trunks to supply the anterior parts of the body.

3. Innominate Artery.-This is the larger of the two main branches of the aorta. A short distance from the heart the innominate gives off three large branches. The first of these is the left common carotid and near it is the right common carotid. The two carotids run forward on either side of the trachea and supply blood to the head and neck. The remaining part of the innominate is continued as the right subclavian, which takes blood to the right arm.

4. Left Subclavian Artery.-This is the other main trunk of the thoracic aorta. It carries blood to the left arm.

It may be seen that the main arteries to the anterior part of the body arise unsymmetrically from the aortic arch. There are great variations in different species in this respect.

From here on follow the vessels on one side only.

5. Vertebral Artery.-Arising from the subclavian and leading directly to the vertebral column, it enters the foramen transversarium of the sixth cervical vertebra and passes to the head. It supplies the muscles of the neck, and the spinal cord and brain. Do not trace it beyond its entry in to the backbone. 
6. Internal Mammary Artery.-This arises on the ventral side of the subclavian at about the same level as the vertebral and runs caudally on the inner surface of the sternum. It is best seen when removing the thoracic body wall.

7. Axillary Artery.-Several other branches are given off from the subclavian before it leaves the thoracic cavity and becomes the axillary artery. The axillary supplies the arm and muscles of the shoulder. Trace the main branches.

8. Internal and External Carotid Arteries.-Follow the common carotid and observe that it passes to the head, giving off small branches on the way. It eventually gives rise to the internal carotid, which passes to the tympanic bulla and enters the skull, and the external carotid, which divides into several smaller branches supplying the lips, floor of the mouth, tongue and portions of the face.

Turn again to the aorta and follow it posteriorly.

9. Intercostal Arteries.-There are about ten pairs of these that leave the aorta after it reaches the dorsal side. They supply the muscles of the back, intercostal spaces, and the spinal cord.

io. Lumbar Arteries.-These correspond to the intercostals in the lumbar region. There are several pairs of them. The first two pairs originate in the thorax.

I I. Coeliac Artery.-This is a single large branch from the abdominal aorta arising near the point where the aorta penetrates the diaphragm. It divides into three branches.

a. The hepatic artery, arises nearest to the origin of the coeliac and passes directly to the liver. Near the pylorus it sends a branch to the stomach and intestines.

b. The gastric leads to the stomach.

c. The splenic, the largest of the three branches, divides and supplies the spleen and pancreas.

i2. Superior Mesenteric Artery.-This arises from the aorta just caudal to the coeliac and may be larger than the coeliac. It sends branches to the small intestine, pancreas, and parts of the colon. The branches follow the mesenteries and are paralleled by veins.

i3. Adrenolumbar Artery.-Arising from the aorta, one on either side about two centimeters caudal to the superior mesentcric, each supplies the muscles of the dorsal body wall. 
I4. Renal Arteries. - These arise from the aorta and pass directly to the kidneys. Each usually divides before entering the kidney.

I5. Internal Spermatic Arteries (ovarian in the female). These arise from the aorta posterior to the kidneys. In the male each passes with the vas deferens to the testis and scrotum; in the female the ovarian leads to the ovary and cranial end of the uterus.

i6. Inferior Mesenteric Artery.-This vessel arises from the aorta at about the level of the last lumbar vertebra and supplies the colon and rectum.

i7. Illo-lumbar Arteries.-These two arteries arise from the aorta about two centimeters caudal to the inferior or mesenteric and pass to the iliopsoas muscles along the dorsal body wall.

I8. External Iliac Arteries. -The aorta divides and forms the two external iliacs which go to the legs. After leaving the body cavity they are known as femoral arteries.

I9. Hypogastric Arteries.-These usually arise from a continuation of the aorta, but may come from one of the external iliacs. Their branches are very variable, but supply mainly the urogenital organs, rectum, and certain pelvic muscles.

20. Sacralis Artery.-This is the continuation of the aorta into the sacral and tail regions.

21. Profunda Femoris Artery.-Originating from the femoral artery at the point where it leaves the abdominal cavity, it divides into branches going to the tissues of the median surface of the thigh and to the ventral wall of the abdomen. The remainder of the femoral passes down the leg.

22. Femoral Artery. - The femoral is the large artery of the leg. Trace the main branches.

Internal Anatomy of the Heart of the Cat

Remove the auricular appendages and the dorsal wall of each auricle, except where the veins enter. Insert the point of the scissors into the pulmonary artery and continue the cut through the right ventricle. Bisect the left ventricle into dorsal and ventral halves. Remove any clotted blood that may be present. It should now be possible to clearly see the internal structures of the heart. 
In the auricles locate the pulmonary veins and venae cavae. Near the opening of the inferior vena cava is the entrance of the coronary sinus. The interauricular septum possesses a thin area, the fossa ovalis, which may be felt by running a finger over the septum. In fetal life there is an opening, the foramen ovale, between the two auricles.

The wall of the right ventricle is distinctly thinner than that of the left. The columns of muscle on the inner surfaces are known as trabeculae. The opening between right ventricle and right auricle is guarded by the tricuspid valve, so named because it consists of three membranous flaps, one dorsal, one ventral, and one on the inter-ventricular septum. The valve between the left auricle and left ventricle is the bicuspid or mitral valve. Numerous strands of connective tissue, the chordae tendineae join the flaps of the valves to the walls of the ventricles or to papillary muscles (muscular projections of the walls). The aorta leaves the left ventricle on the right side; the pulmonary artery leaves the right ventricle on the left side. The entrances to both aorta and pulmonary artery are guarded by semilunar valves.

Study the structure and action of all of the valves of the heart. Understand how they operate and at what phases of the heart beat each valve is open and closed. If necessary, consult physiology textbooks. 


\section{THE UROGENITAL SYSTEM}

In all vertebrates the organs of reproduction and those concerned with the elimination of nitrogenous wastes are so closely associated that it is convenient to study them together. Usually part of one system forms also part of the other.

The following directions apply to mature specimens. In immature animals it is sometimes difficult to locate all parts of the urogenital system. After dissecting your own specimen exchange with someone who has made a dissection of the opposite sex. DO NOT TAKE SOMEONE ELSE'S SPECIMEN WITHOUT THE OWNER'S PERMISSION.

\section{Urogenital Organs of the Male Shark}

The testes are the large bodies in the anterior part of the body cavity dorsal to the liver. Each is attached to the dorsal body wall by a mesentery, the mesorchium.

The kidneys are long, slender, brown bodies extending nearly the length of the body cavity along the dorsal wall. The posterior ends are thicker than the anterior and probably function more in excretion. The shark kidney is a mesonephros or Wolfian body.

Remove the peritoneum from the surface of one kidney; the long convoluted vas deferens or Wolffian duct is now visible on the ventral surface of it. Posteriorly the Wolffian duct straightens out and expands to form a seminal vesicle. Anteriorly, small tubules may be seen passing through the mesorchium from the testis and entering the anterior part of the kidney. These are the vasa efferentia, which join the kidney tubules. The tubules of the kidney then connect with the Wolffian duct.

At the posterior end of the kidney, near the median line and partly embedded, is the ureter or accessory mesonephric duct. Do not mistake the heavy ligament for this.

Cut open the cloaca and find the urogenital papilla and the opening of the rectum. Open the urogenital papilla and find an 
expanded sac, the urogenital sinus, into which the seminal vesicle and ureter empty. Try to find the openings of these.

The elasmobranchs are peculiar in that there are two mesonephric ducts. In most animals with mesonephric kidneys a single duct serves for the passage of both urine and sperm.

\section{Urogenital Organs of the Female Shark}

The ovaries are elongated bodies on each side of the anterior part of the body cavity. Each is held to the dorsal body wall by a fold of the peritoneum, known as the mesovarium. The lobulated character of the ovaries is due to sac-like follicles, each of which contains an egg. The size of the ovaries depends upon the state of development of these eggs. The ovaries are not connected with any duct, but the eggs when ripe simply break through the ovarian wall into the body cavity.

On the inner surface of the ventral body wall, near the anterior end of the liver, is a loose membrane with a longitudinal slit. This slit is the ostium tubae, the common opening of the two oviducts or Mullerian ducts. The oviducts pass dorsally, one on either side of the liver, and then caudally. The posterior swollen portion of each duct is the uterus. The ripe eggs that have entered the body cavity from the ovary, pass through the ostium tubae, enter the narrow part of the oviduct, and finally reach the uterus. In viviparous sharks, like this species, the young develop here. Between uterus and ostium there may be found a small swelling, the shell gland. The Mullerian ducts enter the cloaca close together and dorsal to the urinary papilla.

The kidneys of the shark are known as Wolffian bodies or mesonephroi. They consist of a pair of elongated structures extending almost the whole length of the body cavity, dorsal to the peritoneum and near the median line. The posterior part of each is wider and thicker than the anterior, and apparently is the only part that functions as an excretory organ in adults.

The ureter or accessory mesonephric duct runs along the median edge of the posterior part of the kidney, somewhat cmbedded in tissue. Beginning at the lateral edge of the kidney remove the peritoneum to expose this duct. The ducts from 
the two sides open into the urinary sinus, which lies in the urinary papilla in the cloaca. The Wolffan duct is difficult to locate in females. It lies on the ventral side of the anterior part of the kidney; in immature females it is directly beneath the oviduct, and in mature adults along the attachment of the mesentery supporting the oviduct. It empties with the Wolffian duct into the urinary sinus of the urinary papilla.

\section{Urogenital Organs of the Male Necturus}

The testes are elongated and lie dorsal to the small intestine. Each is supported by a mesentery, the mesorchium. The kidneys or mesonephroi lie dorsal and posterior to the testes. The anterior end may not be excretory in function. The Wolffian or mesonephric ducts, much coiled, lie along the lateral borders of the kidneys and serve for the passage of both the sperm and the excretions of the kidneys. The vasa efferentia, tubes which carry sperm from the testis to the kidney, may be seen as white ducts in the mesorchium. The sperm pass from the vasa efferentia through the tubules of the kidney to reach the Wolffian duct. Trace the Wolffian ducts to the cloaca.

Slit open the cloaca and try to find the entrances of the Wolffian ducts. Find also the entrance of the large intestine and of the urinary bladder. How does urine get in to the bladder?

\section{Urogenital Organs of the Female Necturus}

The ovaries are sac-like structures containing the eggs. Each is supported by a mesentery, the mesovarium. The large white coiled tubes running the length of the body cavity, lateral to the ovaries, are the oviducts. Trace the oviduct forward and find the thin-walled expanded end, with an opening, the ostium, leading into it. Posteriorly the oviducts join the cloaca.

The kidneys or mesonephroi lie dorsal to the ovaries and median to the oviducts. The Wolffian or mesonephric ducts, much smaller here than in the male, lie along the lateral borders of the kidneys. To see where the mesonephric ducts and the oviducts enter the cloaca, free the cloaca from the body wall. Observe also the entrance of the urinary bladder and of the intestine into the cloaca. 
Urogenital Organs of the Cat Common to Both Sexes

Kidneys.-These are paired, bean-shaped structures lying against the dorsal body wall on the iliopsoas muscle in the abdomen. The right kidney is somewhat anterior to the left. As in all other vertebrates the kidneys lie outside the coelom and are covered with peritoneum on the ventral side only. Remove the peritoneum and any fat that may be covering the kidney. The notch on the median side is known as the hilus. Here may be found the renal artery coming from the dorsal aorta to the kidney, the renal vein extending from the hilus to the inferior vena cava, and the ureter.

The ureter is a white tube, sometimes deeply embedded in fat, extending from the hilus of the kidney to the base of the urinary bladder. In removing the fat and in tracing the ureter be very careful not to cut any blood vessels or other ducts. In male cats watch particularly for the vas deferens, which crosses the ureter a short distance from its point of attachment to the bladder. Urine escapes from the bladder to the outside by means of the urethra.

Split one kidney into dorsal and ventral halves. Observe that it is covered with a loose fibrous coat, the renal capsule, which is continuous with the walls of the ureter. The kidney may be seen to consist of an outer layer, the cortex, and an inner layer, the medulla. Near the hilus the ureter expands into a. cavity, the pelvis, into which a papilla projects.

Adrenal Bodies.-These are two small ovoid bodies more or less embedded in fat, one lying near the anterior end of each kidney. They are endocrine glands and are not part of the urogenital system.

With bone forceps cut through the pelvic girdle on either side of the mid-ventral line and remove the central section of bone. Work carefully so as not to injure the underlying tissues. In the male be especially careful not to cut the spermatic cords, which lie externally.

\section{Reproductive Organs of the Male Cat}

Testis and Vas Deferens.-The scrotum is the external pouch of skin, ventral to the anus. It is divided internally 
into right and left halves, within each of which lies a testis. Cut open the scrotum so as to expose a testis. If the membranes covering the testis are removed, the epididymis, the first part of the duct of the testis, may be seen on one side. It appears as a flattened band, which passes posteriorly into the vas deferens. The vas deferens together with the spermatic artery and spermatic vein, lies within the spermatic cord, which enters the body cavity through the inguinal canal. Within the body cavity the vas deferens leaves the spermatic artery and vein, loops over the ureter, and with the vas deferens of the other side, passes through the prostate gland and enters the urethra.

Urethra And Penis.-The urethra extends from the base of the urinary bladder to the outside, passing through the penis along its ventral side. From the point where the vasa deferentia enter it, the urethra serves for the passage of both urine and spermatozoa, and is thus in reality a urogenital sinus. At the base of the penis are a pair of Cowper's glands which also pour their secretions into the urethra. Examine the end of the penis and observe the fold of integument forming the prepuce, which ensheathes the roughened glans penis.

\section{Reproductive Organs of the Female Cat}

Ovaries.-These are small ovoid bodies lying just posterior to the kidneys. Occasionally small grayish spots, the Graafian follicles, may be seen on them; larger corpora lutea follicles, from which eggs have been discharged, are sometimes present also. As in other vertebrates, the ovary has no direct connection with any duct; it does, however, lie in close proximity to the mouth of the oviduct.

Genital Ducts.-Each oviduct (usually called Fallopian tube in mammals) begins with an expanded opening, the ostium tubae, lying lateral to the ovary. From the ostium the oviduct passes in a curve around the ovary and then expands into the uterus.

The uterus is continuous with the oviducts and consists of two long tube-like cornua (horns) which meet near the base of the bladder to form the body of the uterus. The young develop in the cornua and not in the body. In pregnant cats the 
cornua may be greatly swollen. The posterior end of the uterus is telescoped into the vagina, forming a slight swelling where the uterus and vagina overlap. The telescoped portion of the uterus is known as the cervix uteri (meaning neck of the uterus); the opening between uterus and vagina is the os uteri (meaning mouth of the uterus). These structures may be seen by splitting open the vagina and the body of the uterus.

The vagina extends posteriorly until it is joined by the urethra from the bladder to form the urogenital sinus, a small space common to both the excretory and the reproductive systems. The external opening of the urogenital sinus lies ventral to the anus and is known as the vulva. Cut open the urogenital sinus and find the opening of the urethra. 


\section{THE NERVOUS SYSTEM}

The nervous system is composed of four parts: (I) the central nervous system, composed of brain and spinal cord; (2) the peripheral nervous system, consisting of the cranial and spinal nerves; (3) the sympathetic nervous system, which regulates involuntary activities; (4) the sense organs. The brain, cranial nerves, and certain of the sense organs will be dissected.

\section{SENSE ORGANS}

\section{EAR of the Shark}

Locate again the openings of the endolymphatic ducts on the dorsal side of the head between the spiracles. It will be remembered from the study of the shark skull that the endolymphatic ducts connect with the inner ear. Remove the skin from the head except for a small patch around the openings of the endolymphatic ducts. This patch will aid as a landmark in locating the position of ear structures. Clean away the muscles and connective tissue of one side until the cartilage of the skull is exposed in the region posterior to the eyes.

Examine a prepared skull of a shark and locate the position of the endolymphatic fossa and the semicircular canals of the ear. Turn again to your own specimen and carefully shave off the cartilage between the endolymphatic ducts and the spiracle. Be careful not to injure the brain which lies in the mid-dorsal region, or the nerves that penetrate the cartilage.

Watch for the appearance of the semi-circular canals through the cartilage. The first canals to be seen will be the anterior vertical and the posterior vertical canals. Leave them in place, but dissect the cartilage from around them. Do not injure the structures at the ends of the canals. Continue the dissection, watching for the horizontal canal, which lies lateral to and deeper than the others. The three semi-circular canals connect with a thin-walled sac, the vestibule, lying beneath them. Leave the organs embedded in the cranium, but continue removal 
of cartilage until all parts are exposed. A good dissection of the shark ear requires patience and technique.

Both ends of each semi-circular canal join the vestibule. On one end of each is a small bulb, the ampulla. Observe that the semi-circular canals are at right angles to one another. The vestibule is divided into two regions which are not easily distinguished. The larger dorsal part is the utriculus. The semi-circular canals arise from this. The ventral portion is the sacculus to which the endolymph duct is joined.

The ear of the shark, as in other vertebrates, functions for the reception of sound vibrations and as an organ of equilibrium. In fishes the ear consists of an inner ear only; there is no middle ear or external ear such as may be found in higher forms.

\section{Eye of THE SHARK}

Muscles of the Eye.-Remove the tissues from around the eye of the shark on the same side of the head as the dissection of the ear. Cut away the cartilage from above the eye, being careful not to injure the brain or the nerves. If the dissection is carefully made, six slender muscles that function in moving the eyeball in various directions may be seen. Four of these muscles originate from the posterior part of the orbit. These are the rectus muscles. The two originating from the anterior part of the orbit are the oblique muscles. The names of the individual muscles indicate their position.

a. The superior oblique is the more anterior of the two muscles inserting on the dorsal side of the eye. It is supplied by the fourth cranial nerve.

b. The superior rectus inserts near the superior oblique on the dorsal side of the eye. It is supplied by the third cranial nerve.

c. The inferior oblique inserts on the ventral side of the eye and may be seen by moving the eye backward and medially, or by cutting the superior oblique. It is innervated by the third cranial nerve.

d. The external rectus is inserted on the posterior surface of the eyeball. It is supplied by the sixth cranial nerve.

c. The internal rectus inserts on the anterior end of the eyeball and is innervated by the third cranial nerve. 
f. The inferior rectus inserts on the ventral side of the eye. It may be seen by cutting the other muscles at their insertions. It is innervated by the third nerve.

On the median side of the eyeball observe the large optic nerve. Also, in the posterior corner of the orbit among the rectus muscles, find the optic pedicel, a cartilaginous stalk for supporting the eyeball.

Anatomy of the Eyeball.-Remove the eyeball from the orbit, cutting any tissues that may hold it.

The outermost covering of the eyeball is the sclerotic coat, composed of very tough connective tissue. The muscles of the eye are attached to it. A transparent continuation of the sclerotic coat, the cornea, extends over the front of the eye. The pupil is the opening that may be seen through the cornea.

Remove the dorsal wall of the eyeball and observe the structures within. The large cavity in the posterior part is filled during life with a fluid, the vitreous humor. The pigmented layer just within the sclerotic coat is the choroid coat, and the thin white membrane within this is the retina, the sensory part of the eye.

The lens is held in place by a suspensory ligament attached to the choroid coat. The iris, a pigmented extension of the choroid coat, surrounds the pupil in front of the lens. The iris controls the amount of light entering the eye by regulating the size of the pupil. The cavity between iris and cornea is filled during life with a fluid, the aqueous humor. The aqueous humor and vitreous humor aid the lens in bending the light rays so that they focus on the retina.

The structure of the eye is fundamentally the same in all vertebrates. Examine the model of the human eye for comparison with the eye of the shark.

\section{Middle Ear of an Amphibian}

In the frog the ear consists of two regions, an inner ear and a middle ear. In a demonstration dissection of the middle ear observe the columella, a single bone extending from the tympanum across the cavity of the middle ear. What is the evolutionary origin of this bone? The cavity of the middle ear and 
the Eustachian tube, connecting with the mouth cavity, are homologous to the spiracle of the shark.

\section{Mammalian Ear}

Study charts and models of the human ear and be able to identify the various parts. Notice particularly the three bones of the middle ear (malleus, incus, and stapes) and the cochlea of the inner ear. From what are the three bones of the middle ear derived? Be sure that you understand how the ear functions.

\section{BRAIN AND CRANIAL NERVES}

\section{Brain of the Shark-Dorsal Surface}

Slice away the cartilage of the roof of the cranium so as to expose the brain. Nerves will become visible as dissection proceeds. Try not to cut them. They will be identified later.

The brain and spinal cord are covered by a thin membrane, the primitive meninx, which is comparable to the meninges (three membranes) of mammals.

The large anterior part of the brain is the telencephalon. It is composed of indistinctly paired cerebral hemispheres, and in front of these, large swellings, the olfactory lobes. Extending forward from the olfactory lobes are short stalks, the olfactory tracts, which end in olfactory bulbs. Short olfactory nerves extend from the olfactory bulbs to the nasal capsules. The olfactory lobes, tracts, and bulbs constitute the rhinencephalon.

Posterior to the cerebral hemispheres there is a narrow depressed region, the diencephalon. A thin layer of blood vessels, known as the choroid plexus, covers the third ventricle. The epiphysis, a slender thread-like structure, arises from this part of the brain. It was probably destroyed in removing the roof of the cranium.

The mesencephalon or midbrain lies behind the diencephalon. It consists mainly of two large optic lobes.

The cerebellum or metencephalon lies posterior to the optic lobes and somewhat overlaps them. Shallow cross lines give the cerebellum the appearance of being divided into four parts. 
The part of the brain remaining posterior to the cerebellum is the medulla oblongata or myelencephalon. The medulla is continuous posteriorly with the spinal cord. If the thin covering of the medulla, the choroid plexus, is removed, a large triangular depression is visible. This is the fourth ventricle. The lateral extensions of the medulla at its anterior end are the restiform bodies.

\section{Cranial Nerves of the Shark}

The ten pairs of cranial nerves of the dogfish need be dissected on one side only. They are numbered, beginning anteriorly.

I. Olfactory.-The olfactory nerve consists of a bundle of short fibers extending from the olfactory bulb to the nasal capsule.' It is a sensory nerve.

II. Optic.-The optic nerve arises from nerve endings in the retina of the eye and extends to the ventral side of the diencephalon, where it crosses the nerve from the other side. This relation will be better understood after the ventral surface of the brain is studied. It is a sensory nerve.

III. Oculomotor.-This nerve arises from the mesencephalon on the ventral side. It may be seen as a slender thread entering the orbit back of the optic nerve. It is a motor nerve and supplies four of the eye muscles, namely, the internal, inferior, and superior rectus, and the inferior oblique.

IV. Trochlear. - This begins on the dorsal side of the brain behind the optic lobes, and beneath the anterior part of the cerebellum. It is very slender. It passes through the wall of the orbit dorsal to the optic nerve. It is motor in function and supplies the superior oblique muscle of the eye.

VI. Abducens.-The sixth nerve is best studied before the fifth. This is a slender nerve arising from near the mid-ventral line of the medulla. It is a motor nerve and supplies the external rectus muscle of the eye.

V. Trigeminal.-The fifth, seventh, and eighth nerves arise very close together from the side of the medulla. The separate roots of these three nerves are difficult to distinguish. The trigeminal enters the orbit and immediately divides into several branches. It is both motor and sensory. 
a. The superficial opthalmic branch of the trigeminal is joined by a similar branch of the seventh nerve to form a large trunk. It passes anteriorly on the dorsal part of the median wall of the orbit, penetrates the cartilage of the skull, and is distributed to the dorsal side of the head.

b. The infraorbital nerve, made up of the maxillary branch of the trigeminal and the buccal branch of the seventh, is a large white band passing under the eye on the floor of the orbit. It ends in several branches. The maxillary fibers innervate the skin and the ampullae on the ventral side of the head.

c. The mandibular branch arises ventral to the infraorbital and passes along the posterior wall of the orbit to supply muscles of the lower jaw and gill arches, and also to innervate the sense organs of the skin.

VII. Facial. - This nerve is both motor and sensory. Its origin with the fifth nerve has already been mentioned. It divides into three branches.

a. The superficial opthalmic is bound in the same sheath with the similar branch of the fifth, and with it, goes to the sense organs of the head, supplying part of the lateral line organs.

b. The buccal branch of the seventh and the maxillary branch of the trigeminal compose the infraorbital trunk, as has already been mentioned. The buccal also supplies part of the lateral line organs.

c. The hyomandibular branch lies just under the skin posterior to the spiracle. Trace it back toward the brain. It innervates the sense organs of the head, the muscles of the hyoid arch, the floor of the mouth and the tongue.

VIII. Auditory.-This arises with the fifth and seventh and supplies the ear. It is a sensory nerve.

IX. Glossopharyngeal. - The ninth nerve arises from the medulla posterior to the eighth and leaves the skull at the posterior-lateral corner. It passes through the auditory capsule and then divides and goes to the gill region. It is both motor and sensory.

$\mathrm{X}$. VAGus. - This nerve originates from the side of the medulla, posterior to the ninth, by several roots. It is a large nerve and widely distributed. After passing through the posterior wall of the skull it divides into many branches to 
supply part of the lateral line system, gill region, oesophagus, stomach, and other viscera. It is both motor and sensory in function.

\section{Brain of the Shark-Ventral Surface}

After demonstrating your dissection to the instructor, cut the cranial nerves and remove the brain from the cranium. Work carefully so as not to injure the ventral surface.

Identify as many as possible of the structures mentioned for the dorsal surface.

The optic chiasma is the place where the optic nerves cross on the ventral side of the diencephalon. The optic tracts extend posteriorly and dorsally from the optic chiasma and lead to the optic lobes.

The infundibulum is the large ventral bulge of the diencephalon posterior to the optic chiasma. It consists largely of two lobes, the lobi inferiores.

The pituitary body may be partly destroyed in the dissection, as it fits into a depression in the floor of the skull. It extends caudally from between the lobi inferiores.

\section{Ventricles of the Shark Brain}

With a sharp knife or a razor blade remove the dorsal side of the brain so as to expose the cavities within. The cavities of the telencephalon are the first and second, or lateral ventricles. They extend forward into the olfactory bulbs. Posteriorly they connect by a passage, the foramen of Monro, with the third ventricle, which is the cavity of the diencephalon. The roof of the third ventricle is the choroid plexus. The large triangular cavity in the medulla is the fourth ventricle, previously mentioned. It is also covered by a choroid plexus. A narrow passage, the iter, joins the third and fourth ventricles. The iter connects with the optic ventricles of the optic lobes and the cerebellar ventricle of the cerebellum.

\section{Brain of the Cat}

Remove the eyes and lower jaw and clean the skull down to the bone. Detach the head, together with a few neck vertebrae, from the rest of the body. With the bone forceps make a 
small hole in the skull and pick off the bones piece by piece from the roof and sides of the head so as to expose the brain and beginning of the spinal cord. On the ventral side of the skull cut the membranes around the nerves. The pituitary body of the brain fits into a depression, the sella turcica, of the sphenoid bone. If possible cut the sphenoid so as to leave the pituitary attached to the brain. Keep the brain in a jar of formalin when not studying it.

Meninges.-These are membranes covering the brain and spinal cord. There are three in mammals. The outermost membrane is the dura mater, which is quite thick and tough. The pia mater is the delicate inner membrane that follows closely all the folds of the brain surface. Between these two membranes is a third, the arachnoid, very delicate and hard to see. The spaces between the membranes are filled with fluids during life. Amphibians, reptiles, and birds do not have the arachnoid, while fishes have only one membrane, the primitive meninx.

Dorsal Surface of the Brain.-Remove the dura mater. The olfactory bulbs appear as relatively small swellings at the anterior end of the brain. The olfactory nerves going to the nostrils pass forward from them. The bulbs may have been broken in removing the brain from the skull.

The large convoluted cerebral hemispheres lie posterior to the olfactory bulbs and make up a large proportion of the brain. The convolutions are known as gyri, and the grooves between the gyri as sulci. The two hemispheres are separated from each other by a deep longitudinal fissure. By gently spreading the hemispheres a thick white mass may be seen at the bottom of the fissure. This is the corpus callosum, consisting of nerve tracts connecting the two hemispheres. It will be mentioned again later.

The cerebellum lies directly behind the cerebral hemispheres, consisting of a median part, the vermis and two lateral hemispheres. Between the cerebellum and the cerebral hemispheres lies the mesencephalon, concealed by the hemispheres.

The cerebellum overhangs the medulla oblongata posteriorly. Beneath the vermis of the cerebellum is the cavity of the fourth ventricle of the medulla. The fourth ventricle is normally covered by a vascular membrane, the choroid plexus. The medulla narrows posteriorly to form the spinal cord. 
Ventral Surface of the Brain.-Extending posteriorly from the olfactory bulbs to the middle of the cerebral hemispheres are white olfactory tracts. These end in the pyriform lobes of the cerebral hemispheres.

In the mid-ventral line is the optic chiasma where the optic nerves cross. The optic tracts extend back from the chiasma.

The region behind the optic chiasma is the diencephalon. The median rounded elevation is the tuber cinereum, to which is attached the pituitary body. If a small aperature shows in the tuber cinereum, the pituitary is not present; it was probably torn off in removing the brain. Two small mammillary bodies, not distinctly separated from the tuber cinereum, lie behind the pituitary. Just posterior to these, near the median line, are the roots of the third or oculomotor nerve. Lateral to the third nerve roots and the mammillary bodies, and partly covered by the pyriform lobes, are the cerebral peduncles. 'These are bundles of fibers connecting the cerebral hemispheres with the rest of the brain and the spinal cord. The fourth or trochlear nerves extend as slender threads across the peduncles.

The transverse band of fibers posterior to the peduncles is the pons Varolii. At the posterior borders of the pons arise the fifth or trigeminal nerves.

The medulla oblongata occupies the region posterior to the pons. A median ventral fissure extends its entire length and continues down the spinal cord. The longitudinal bands of fibers on either side of the ventral fissure are the pyramids. Several cranial nerves arise from the medulla. The sixth or abducens arises from the pyramids near the median line. The seventh or facial nerve roots are just posterior to the fifth. The roots of the eighth or auditory nerve are posterior to the seventh. The ninth or glossopharyngeal and the tenth or vagus arise near together by several rootlets. The numerous roots of the eleventh or spinal accessory arise in a line posterior to the vagus. The roots of the twelfth or hypoglossal emerge from the lateral borders of the pyramids.

Brain Bisected.-Cut along the longitudinal fissure between the cerebral hemispheres so as to divide the brain into right and left halves. Examine the median surface of one half.

The Commissures. - These are bundles of fibers connecting the two sides of the brain. Find again the corpus callosum, 
located at the base of the cerebral hemispheres. This is the largest commissure of the brain. The anterior and posterior ends are slightly swollen. A band of fibers, the fornix, extends ventrally from about the middle of the corpus callosum. The anterior commissure is a small cord of fibers cranial to the ventral end of the fornix. The middle commissure is a large bundle of fibers posterior to the fornix. It is located in the middle of the third ventricle and is part of the thalamus, to be mentioned later. The posterior commissure is a small group of fibers posterior to the middle commissure.

The ventricles of the brain of the cat occupy positions similar to those of other vertebrates. The lateral ventricles are small cavities in the cerebral hemispheres. They may be found by making a longitudinal slit through the corpus callosum and lifting up the cerebral lobes. Each lateral ventricle connects by a foramen of Monro to the third ventricle, which surrounds the middle commissure and extends into the pituitary gland. The iter is a narrow passage under the cerebellum, connecting the third and fourth ventricles. The fourth ventricle is the cavity of the medulla and is continuous with the canal of the spinal cord.

Anterior to the cerebellum and dorsal to the iter are two rounded swellings in each half of the brain. These are the corpora quadrigemina, corresponding to the optic lobes of lower vertebrates. The cerebral peduncles form the floor of the iter.

The branched white tracts in the cerebellum constitute the arbor vitae.

Remove the dorsal wall of the cerebral hemisphere of one half of the brain. In doing so observe that the outside of the brain is gray and the inside white. The gray layer is the cortex. Identify again the corpora quadrigemina. The prominent clevation anterior to these is the thalamus, a large ganglion. Anterior to the thalamus is another ganglion, the corpus striatum, which forms part of the floor of the lateral ventricle.

Examine the series of vertebrate brain models and identify the principal structures on each. Observe the marked differences in some of the parts. 



A) Sy

gyong

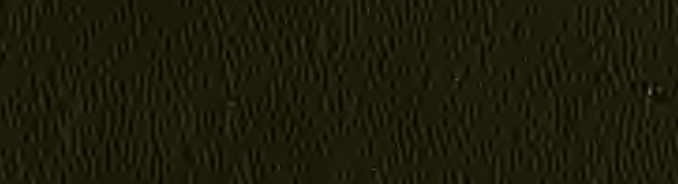

a 年,

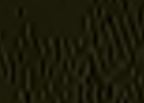

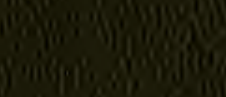


